NASA Technical Memorandum 87294

AIAA-86-1611

NASA-TM-87294

19860022960

\title{
Perspectives on Dilution Jet Mixing
}

\section{FOR REFERENCF}

MOT TO BC TAKEI FHOM THIS nOOU

J.D. Holdeman

Lewis Research Center

Cleveland, Ohio

and

R. Srinivasan

The Garrett Turbine Engine Company

Phoenix, Arizona

\section{LIBPAPY BOPY}

$$
\text { SE: }
$$

IANGLEY RESEARCH CENTER LURRARY, NASA

HRUTIOH, YIRGIHIA

March 1986 


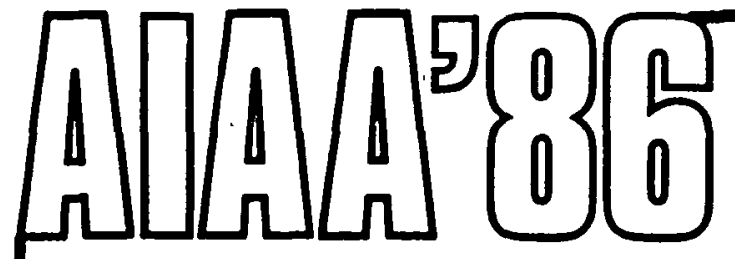

AIAA-86-1611

Perspectives on Dilution Jet Mixing

J.D. Holdeman, NASA Lewis Research

Center, Cleveland, $\mathrm{OH}$; and R. Srinivasan,

The Garrett Turbine Engine Company,

Phoenix, AZ

\section{AIAA/ASME/SAE/ASEE 22nd Joint Propulsion Conference June 16-18, 1986/Huntsville, Alabama}




\section{Perspectives on Dilution Jet Mixing}

by J. D. Hol deman*

nasa Lewis Research Center, cleveland, Ohio

and

R. Srinivasan*-

The Garrett Turbine Engine Company, Phoenix, Arizona

\section{Abstract}

A microcomputer code which displays 3-D oblique and 2-D plots of the temperature distribution downstream of jets mixing with a confined crossflow has been used to investigate the effects of varying the several independent flow and geometric parameters on the mixing. Temperature profiles calculated with this empirical model are presented to show the effects of orifice size and spacing, momentum flux ratio, density ratio, variable temperature mainstream, flow area convergence, orifice aspect ratio, and opposed and axially staged rows of jets.

\section{Nomenclature}

$$
\begin{aligned}
& A_{\lrcorner} / A_{m} \quad=\text { jet-to-mainstream area } \\
& =(p i / 4) /\left(\left\{S / H_{0}\right)\left(H_{0} / D\right) \geq\right\} \\
& \text { AR = orifice aspect ratio (W/L) } \\
& \text { C } \quad=\left(S / H_{0}\right)((J) \cdot 5) \text {; Eq. (3) } \\
& \text { Ca = orifice discharge coefficient } \\
& \text { D } \quad \text { orifice diameter } \\
& \text { D, }=(D)\left(\left\{C_{\theta}\right) \cdot-0\right) \\
& \text { DR = jet-to-mainstream density ratio } \\
& =\left(T_{m} / T_{f}\right) \\
& \mathrm{dH} / \mathrm{dx}=\text { duct convergence rate } \\
& \text { Ho = duct height at injection } \\
& \text { location } \\
& \text { Han = effective duct height } \\
& =H_{0} \text { except for opposed rows } \\
& \text { of jets with centerlines } \\
& \text { in-1 ine; see Appendix }
\end{aligned}
$$

- Senior Research Engineer. Aerothermochemistry Branch. Member AIAA

* Senior Engineering Specialist, Combustion Engineering Sciences.

\section{This paper is declared a work of the U.S. Government and is} not subject to copyright grotection in the United States.
= jet-to-mainstream momentum flus ratio

$=(D R)(R)=$

$M \quad$ jet-to-mainstream mass $f 1$ ux ratio $=(D R)(R)$

R = jet-to-mainstream velocity ratio $=\left(V_{1} / U_{m}\right)$ spacing between orifice centers spacing between orifice rows

= temperature

$=$ jet exit temperature

= mainstream temperature

THETA

= temperature difference ratio

$=\left(T_{m}-T\right) /\left(T_{m}-T_{j}\right)$; Eq- (1)

THETA

= maximum temperature difference ratio in a vertical profile; see Fig., 4

THETAEE = Equilibrium THETA

$=w_{\mathcal{J}} / w_{\tau}$

THETA $_{m 1 m^{-}}=$minimum temperature difference ratio below the centerline (for top injection); see Fig. 4

$$
\begin{aligned}
& \text { THETAm1 } n^{-}=\text {minimum temperature difference } \\
& \text { ratio above the centerline } \\
& \text { (for top injection); see Fig. } 4 \\
& \text { U } \quad \text { = velocity } \\
& U_{m} \quad \text { = mainstream velocity } \\
& v_{1} \quad=\text { jet velocity } \\
& w_{J} / w_{T}=\text { jet-to-total mass flow ratio } \\
& =\frac{(((D R)(J)))-0\left(C_{a}\right)\left(A_{J} / A_{m}\right)}{1+((D R)(J)) \cdot \sigma)\left(C_{d}\right)\left(A_{s} / A_{m}\right)} \\
& W_{1} z^{+} \quad=\text { jet half-width below the } \\
& \text { centerline (for top injection); } \\
& \text { see Fig. } 4 \\
& W_{1} z^{-} \quad=\text { jet half-width above the }
\end{aligned}
$$


centerline (for top injection); see Fig. 4

$\begin{aligned} \times & \text { downstream coordinate } \\ = & 0 \text { at injection plane } \\ = & \text { cross-stream coordinate } \\ & \text { (radial) } \\ = & 0 \text { at injection wall } \\ = & \text { Yeat location of maximum } \\ & \text { THETA in a vertical profile; } \\ & \text { see Fig. } 4 \\ = & \text { lateral coordinate } \\ & \text { (circumferential) } \\ = & 0 \text { at centerplane }\end{aligned}$

\section{Introduction}

The need to design or tailor the temperature pattern at the combustor exit in gas turbine engines, to maximize engine power and $l i f e$, has motivated several investigations on the mixing of jets into a ducted crossflow. These include single and multiple jets injected into a straight duct,, $0.1 \rightarrow$ and $f l o w$ and geometric variations typical of most gas turbine combustors, namely variable temperature mainstream, flow area convergence, and double or opposed rows of jets, either in-line or staggered. $10-1 \theta$

The combustor dilution zone jet-in-crossflow application is a confined mixing problem, with from 10 to 50 percent of the total fiow entering through the dilution jets. The result is that the average temperature of the exiting flow may differ significantly from that of the entering mainstream flow. To control or tailor the combustor exit temperature pattern it is necessary to be able to characterize the exit distribution in terms of the upstream $f l o w$ and geometric variables. This requires that the entire flow field be either known or modeled.

From the data of Refs. 1, 11, 14, and 17, an empirical model was

devel oped $4: 5$ and

extended12,14,17 for predicting

the temperature field downstream of single and double rows of jets mixing with a confined crossflow. It was shown in Refs. 5 and 18 that this model provides a very good predictive capability for the modeled variables within the parameter range of the generating experiments.

In addition to the evolution and extension of empirical modeling schemes, such as the one presented herein, rapid advances have been made recently in the capability of computational fluid dynamics models and their application to complex flows such as jet (s)-in-crossflow. $29-25$ These codes offer several advantages over empiricism, including the prediction of all flowfield quantities (rather than only those for which empirical models exist), flows outside the range of experiments, or flows where empirical assumptions are invalid.

An example of the capability and promise of this type of code is given in Ref. 18, where temperature field distributions calculated using a $3-D$ elliptic

viscous-flow code with a standard k-E turbulence model 22 are compared with measurements from selected cases in Refs. 11, 14, and 17 , and with distributions calculated using the empirical model reported therein. The 3-D code calculations made in Ref. 18 correctly approximated the trends from variation of the independent $f l$ ow and geometric variables, but they consistently exhibited too little mixing. Although improvements in numerics, accuracy, and turbulence models.. should provide more quantitative predictions, there would appear to be a .... continuing need for the empirical model as a near-term design tool.

An interactive microcomputer program (Apple Dos 3.3), based on the model of Ref. 5, was used in Ref. 9 to study the effects of separately varying the independent $f l o w$ and geometric parameters, and to identify the key variables and the relationships among them which characterize the mixing. This code has been extended to model the effects of a variable temperature mainstream, flow area convergence, non-circular orifices, and double rows of jets, both axially staged and opposed.

\section{Description of the Flowfield}

Figure 1 shows a schematic of the dilution jet flowfield for jet injection from the top wall. The temperature field results are presented in three-dimensional oblique views of the temperature difference ratio, THETA, where

THETA $=\frac{\left(T_{m}-T\right)}{\left(T_{m}-T_{.1}\right)}$

A sequence of profile plots of this parameter at several locations downstream of the jet injection plane, for single-sided top injection, is shown in Fig. 2. In the 3-D plots the temperature distribution is shown in $y-z$ planes normal to the main flow direction, $x$. The coordinates $y$ and $z$ are, respectivel $y$, normal and parallel to the orifice row. Note that the jet fluid is identified by the larger values of the THETA parameter (i.e. THETA $=1$ if the local temperature is equal to the jet temperature, and THETA $=0$ if the local temperature is equal to the mainstream temperature). The equilibrium 
THETA for any configuration is equal to the fraction of the total flow entering through the dilution jets, $w_{J} / w_{T}$.

The primary independent geometric variables are the $f l o w$ area convergence, $d H / d x$, orifice aspect ratio, AR, the spacing between adjacent orifices, $S$, orifice diameter, $D$, and, for double rows, the axial spacing between rows, $S_{x}$. The last three of these are expressed in dimensionless form as the the ratio of the orifice spacing to duct height, $S / H_{0}$, the ratio of the duct height to orifice diameter, $H_{o} / D$, and the ratio of the axial spacing to the duct height, $S_{x} / H_{0}$. A

schematic of the several orifice row configurations for which calculations were performed are shown in Fig. 3 .

\section{The Empirical Flowfield Model}

The empirical model for the temperature field downstream of jets mixing with a confined crossflow is based on the observation that properly

non-dimensionalized vertical temperature profiles everywhere in the flow field can be expressed in the following self-similar for $m^{3}$

(THETA - THETA ${ }_{m 1 m}+\infty-$ )

(THETAG - THETA $m n_{n}^{+\infty}$ ),

$-(\ln 2)\left(y-y_{c}\right)=$
$-\exp \left(W_{1} z^{+1-1) z}\right.$

where THETA is the local temperature difference ratio defined by Eq. (1), and

THETA $_{c}$, THETA $m \pm m^{*}$,

THETA ${ }_{m i n^{-}}, W_{1} / 2^{+}$,

$w_{1} / z^{-}$, and $y_{c}$ are

scaling parameters as shown in Fig. 4 Correlations have been developed for each of these in terms of the independent variables $J, S / D, H_{0} / D, Z / S$,

$\mathrm{X} / \mathrm{H}_{2}, \mathrm{~S}_{x} / \mathrm{H}_{0}$, and

the mainstream temperature, and flow area convergence. The correlations used in the present version of the empirical model are given in Refs. 11, 14, and 17, except that the equations describing the effects of orifice aspect ratio have been modified. The complete set of correlation equations is given in the Appendix.

This empirical model has been implemented in a microcomputer program, PROFILES version 2.1. The source code was written in BASIC, uses the Apple DOS 3.3 operating system, and requires $\geq 64 K$ memory. This code is a direct extension of that used in the study in Ref. 9, and provides, as did the previous version, a

three-dimensional oblique view of the temperature field for user supplied values of the several independent variables.

Temperature distributions can be calculated at any user-specified downstream location Profiles may be be shown as "cold" THETA distributions, per Eq. (3), where THETA=1 represents unmixed jet fluid, or as 'hot' THETA distributions where THETA $=1$ represents unmixed mainstream fluid. Individual profiles from the oblique view may also be plotted, either separately or overlayed. All profiles shown in this paper are "cold" THETA distributions; examples of "hot' THETA distributions are shown in Ref. 9.

Different perspectives on the mixing can be obtained by specifying jet injection from the top or bottom duct wall, or with the plane between jets, the midplane, rather than the plane through the orifice center, the centerplane, at the edge in the oblique view. Profiles may be shown across a span of two or more orifices as desired.

For all options, the flow and geometric variables that must be specified are the discharge coefficient, density ratio, momentum flux ratio, orifice spacing-to-duct height ratio, duct height-to-orifice diameter ratio, the axial offset between rows, flow area convergence, mainstream temperature profile, and orifice aspect ratio. Although calculations can be performed for most $f l o w$ and geometric conditions of interest, they will be most reliable for conditions within the range of the experiments on which the correlations are based as shown in Table 1. The density ratio, momentum $f l u x$ ratio, orifice spacing, and orifice size were the primary independent variables. The orifice-to-mainstream area ratio, the jet-to-total mass flow split, and the parameter coupling the spacing and momentum flux ratio, which are derived from the primary variables are also given in the table. Not all combinations of the primary variables in the table were tested; anly those combinations which are within the range given for the derived variables represent conditions that are within the range of the experiments.

\section{Results and Discussion}

Figures 5 to 20 show example variations in THETA profiles as a function of the several independent flow and geometric variables. The orifice configurations for which profiles were calculated are shown in Fig. 3 , with the profile figure/orifice configuration correspondence given in Table 2. Except for configurations with non-circular orifices and profiles spanning more than two orifices in a row, the 
orifice locations are shown schematically on the profile figures. Although all of the conditions for which profiles are shown in this paper do not correspond directly to experimental conditions in Refs. 11, 14 , and 17, many are close, and these are identified in Table 2 .

Orifice Size and Spacing. At constant total orifice area, changes in orifice size and spacing can have a significant influence on the THETA profiles. This is shown in Fig. 5, where (from left to right) jets from closely spaced small orifices under-penetrate and remain near the injection wall, and jets from widely spaced 1 arger orifices over-penetrate and impinge on the opposite wall. These profiles are all at a downstream distance equal to one-half of the height of the duct.

Momentum Flux Ratio. Figure 6 shows a typical increase in jet penetration with increasing momentum flux ratio, at the same downstream distance. Here the hole diameter has been decreased with increasing momentum flux ratio to maintain a constant mass flow ratio between the jets and mainstream.

Density Ratio. The analyses of the experimental data in Ref. 1 suggested that the effect of varying the density ratio was of second order, for $f 1$ ows with a constant momentum $f 1$ us ratio. This was confirmed, over a much broader range of density ratios in Ref. 11, and is illustrated by the profiles in Fig. 7. In part a), the density ratio is varied from .45 (hat jets) to 2.2 (hot mainstream) at $x / H_{0}=$ .5 for the same momentum $f 1 u x$ ratio and orifice geometry as in Fig. 2. The similarity of the profiles in Fig. 7 a) is in sharp contrast to those in parts bl and c) where the density ratio is varied at constant values of velocity and mass flus ratio respectively.

Orifice Discharqe Coefficient. The sixth of the primary independent variables which must be specified is the orifice discharge coefficient. The profile changes which result from variation of this parameter from . 36 to 1 are shown in Fig. 8. Note than the THETA values increase in response to the greater jet air flow as $C_{a}$ increases, but the jet penetration and profile shape remain simi 1 ar.

Coupled Spacing and Momentum F1ux Ratio. Examination of the experimental data in Ref5. 1, 11, 14, and 17 revealed similar jet penetration over a range of momentum $f l u x$ ratios and orifice spacing when these independent variables were coupled. For example, l ow momentum flux ratios require large, widely spaced holes, whereas smaller clasely spaced holes are appropriate for high momentum flux ratios. $x_{0.0}, 9$
As shown in Ref5. 13 and 18, jet penetration and centerplane profiles are similar when the spacing is inversely proportional to the square root of the momentum flux ratio, i.e.:

$S / H_{0}=C /((J) \cdot \nabla)$

For single-side injection, the centerplane profiles are approximately centered across the duct height and approach an $i$ sothermal distribution in the minimum downstream distance when $C=2.5$. Values of $C$ in Eq. (3) which are a factor of $\geq 2$ smaller or 1 arger than the optimum correspond to under-penetration or over-penetration respectively (e.g. Figs. 5 and 6$)$.

Figure 9 shows profiles for different momentum flux ratios, when the orifice spacing is adjusted according to Eq (3). The profiles in parts a) and b) are at downstream distances equal to one-half and two duct heights respectively. Clearly, similar distributions are obtained when $J$ and $\mathrm{S} / \mathrm{H}_{0}$ are coupled; however, it is also evident that flows with smaller momentum flus ratios (1 arger spacing) need greater downstream distances to achieve equivalent mixing.

Orifice Size at Constant Spacing. At the desired coupling between orifice spacing and momentum flux ratio, the profiles remain similar with variation in orifice size. The profiles in the top and bottom rows in Fig. 10 are at downstream distances equal to one-half and two duct heights respectively. The orifice diameter is doubled going from left to right, resulting in a four-fold increase in the ratio of the jet-to-mainstream flow. The result is that the temperature distributions are shifted to higher THETA values, consistent with the larger dilution air flow, but the shape of the distributions remains similar.

Variable Temperature Mainstream. The influence of a non-isothermal mainstream flow on the profiles can be seen by examining Fig. 11. In part a), under-penetrating jets were chosen to cool a hot mainstream near the injection wall; in part b), the jets were positioned to cool a center-hot mainstream; and in part c), over-penetrating jets were chosen to cool a mainstream which is hot adjacent to the opposite wall. The empirical profiles here were obtained by superimposing the upstream profile and the corresponding jets-in-an-isothermal mainstream distribution.

This gives a good approximation to the experimental data as seen in Ref. 18, but it must be realized that this model is only first-order accurate, since with a variable temperature mainstream there can be 
cross-stream thermal transport due to the flow of mainstream fluid over and around the jets (and hence to different $y$ locations), and this is not accounted for in superimposing the distributions.

Flow Area Converqence. Fi gure 12 shows the effect of flow area convergence on the temperature profiles for the same orifice geometry and flow condition as in Fig. 2. In parts a) and b) the duct converges to $1 / 2$ of the injection plane height in a downstream distance equal to $2\left(H_{0}\right)$ and $H_{0}$ respectively

(i.e. $.25 \mathrm{~cm} / \mathrm{cm}$ and $.5 \mathrm{~cm} / \mathrm{cm}$ ). These profiles show increasing jet penetration (with respect to the local duct height) and slightly increased lateral nan-uniformity, but these profiles do not support the observation ${ }^{13}$ that convergence

improves the mixing.

Orifice Aspect Ratio. Temperature distributions from jets issuing from orifice row configurations with bluff and streamlined slots of aspect ratio equal to 2.85 and .35 respectively are shown in $\mathrm{Fig}$. 13. These configurations are shown in rows $I$ and $J$ in Fig. 3 , and have the same orifice spacing and open area as the circulat holes shown in row $E$. The jets from the bluff slots, Fig 13 a), penetrate less and are more

2-dimensional across the orifice centerplane compared to the circular holes, Fig. 2, whereas the jets from streamlined slots, Fig. $13 \mathrm{~b}$ ), are highly

three-dimensional and have deeper penetration. At downstream locations both the slot configurations and the circular holes produce very similar completely mixed temperature distributions.

\section{Slanted Slats. Figure 14 shows}

temperature profiles for the same slot as in Fig. 13, oriented at 45 degrees to the main flow direction. The orifice area and momentum flux ratio for this configuration are the same as for the circular holes in Fig. 2 .

The experimental data in Ref. 16 for this configuration shows that the centerplanes of the jets shift laterally with increasing downstream distance. The empirical model profiles in Fig. 14 illustrate this shift (c.f. Fig. 2), but the asymmetry of the distributions observed in the experimental data is not modelled.

Opposed Rows of In-line Jets. For opposed rows of jets of identical orifice spacing and diameter, with the orifice centerlines in-line, it was shown in Ref. 13 and 18 that the optimum ratio of orifice spacing to duct height is one-half of the optimum value for single-side injection at the same momentum $f 1 u x$ ratio. This is shown by the profiles for two orifice

spacing/momentum flux ratio combinations in
Fig. 15. The profiles in part b) may be compared to the one-side injection profiles at the same orifice area and momentum flux ratio in Fig. 2. Note that $\mathrm{C}=1.28$ (see Eq. (3)) for these cases, or one-half of the optimum value for single-side injection.

A similar case, but with unequal momentum flux ratios on the two sides is shown in Fig. 16. Here the total jet flow is the same as in Fig. $15 \mathrm{~b}$ ), but the plane of symmetry, defined by the momentum balance betweem the opposing rows, is no longer midway across the duct. Note however, that this plane of symmetry maintains an optimum relationship between the orifice spacing and momentum flux ratio on each side. The limiting case, i.e. flow from only one side; is shown in Fig. 16 b).

Qpposed Rows of Staquered Jets. For opposed rows of jets of identical orifice spacing and diameter, with the orifice centerlines staggered, the optimum ratio of orifice spacing to duct height is double the optimum value for single-side injection at the same momentum $f 1 u x$ ratio. $13,2 \mathrm{~s}$ The result of implementing this relationship is shown in Figs. 17 a) and $b$ ). The profiles in part a) may be compared to the corresponding profiles for one-side injection in part c) (this figure is the same as Fig. 2 except that the $z$-span of the figure includes four orifices rather than two). Note that $C=5.13$ for both parts a) and b) in Fig. 17, compared with an optimum value of 2.56 for one-side injection.

It was shown in Ref. 14 and 18 that the empirical model does not compare favorably with the data in this compley case as the fluid dynamic interactions here are not amenable to a direct extension of the simple Gaussian profile and superposition type of modeling appropriate for most of the single-side and opposed-jet cases of interest.

Double Rows of Holes Figure 18 shows temperature distributions for an orifice plate with two in-line rows of jets, for three different axial spacings between the rows. Profiles are shown at downstream distances equal to $.25,-5$, and 1 duct height fram the location midway between the rows. These profiles may be compared with a single row of jets from equally spaced holes in Fig. 2.

It was observed from the experimental profiles in Refs. 1 and 16 that the singleand double-row configurations have very similar temperature distributions, as seen also in these profiles. In this case the empirical model calculations are derived by superimposing the distributions from independent calculations of the two rows.

Figure 19 shows temperature profiles for a 
double-row configuration where the trailing row is staggered with respect to the lead row. In each row in the figure, profiles are given for distances equal to $.25,-5$ and 1 duct height downstream from the trailing row of holes. As in Fig. 18, profiles are shown for varying axial offsets, $S_{N} / H_{0}$, from 1 to

0 . Note that the model does not extrapolate properly as the offset goes to zero, as is evident by comparing Figs. 19 a) and 17 b) since the staggered configuration with $\mathrm{S} / \mathrm{H}_{0}=1$ becomes a single row with $S / H_{0}=.5$ when

$\mathrm{S}_{\mathrm{N}} / \mathrm{H}_{\mathrm{O}}=0$.

Temperature profiles are shown in Fig. 20 for a double-row configuration where one row has twice as many orifices as the other, but with equal orifice areas in each row. In part a), the momentum flux ratio is the same for both rows, but is optimum only for the lead row. The influence of the under-penetration of the trailing row is evident even at the farthest downstream location. In part b), the momentum flus ratio of the lead row is increased resulting in over-penetration of these jets, but this is compensated for by the under-penetration of the trailing row jets and a well mixed distribution is approached with increasing distance downstream. In part c), the geometric configurations of the leading and trailing rows are switched, but with the same momentum flux ratios so that both rows have the optimum combination of spacing and momentum flux ratio. This yields a well mixed profile, as expected, but the result is about the same with the closely spaced row of holes trailing. As with the double rows of in-line and staggered holes, the empirical calculations for this case were obtained by superimposing separate calculations for the two rows.

\section{Limitations and Applicability}

Examination of the empirical model results in Ref. 18 shows that correlation of experimental data can provide a good predictive capability within the parameter range of the generating experiments, provided that the experimental results are consistent with the assumptions made in the empirical model. These models must, however, be used with caution, or not at al1, outside this range.

Considering the results in Ref. 18 in the context of Eq. (3) suggests that in general the empirical model provides good temperature field predictions for single-side injection when $1<C<5$. Similarly, good predictions are obtained for opposed in-line jets provided that $.5<6<2.5$. For opposed rows of staggered jets, satisfactory profiles were obtained with $C$ approximately equal to 5 ; but it was shown in Ref. 14 that opposed staggered jets with lower values of $C$ were best modeled using correlations for the opposed in-line case.

The empirical model does not work well for impinging flows as the experimental temperature distributions are not consistent with the assumption of Gaussian profile similarity in the empirical model. The experimental profiles for conditions giving optimum mixing in opposed staggered-jet configurations are also somewhat at variance with the model assumptions, and al though the agreement with the data is satisfactory in these cases, this must be considered fortuitious.

It should also be noted that the form of the empirical correlations in the current model (and previous versions used in Refs. $4,5,9,11,14$, and 17) precludes their use for semi-confined flows ( 1 arge $H_{\circ} / D$ or $\left.S / D\right)$, single jet flows, or flows in which it is known a priori that the primary assumptions in the model will be invalid.

\section{Summary of Results}

The temperature profiles herein, calculated using at empirical model, for single- and double rows of jets injected into a confined crossflow, show that:

1) Variations in momentum flux ratio and orifice size and spacing can have a significant effect on the resultant temperature profiles.

2) At constant momentum flux ratio variations in density ratio have only a second-order effect on the profiles.

3) Similar temperature distributions are obtained, independent of orifice diameter, when orifice spacing and momentum flux ratio are coupled.

4) The mixing of jets with a variable temperature mainstream can be approximated by superimposing the jets-in-an-i sothermal-mainstream and upstream profiles.

5) Flow area convergence results in slightly increased $j$ et penetration and cross-stream mixing, but the lateral profiles are less uniform that for the straight duct case.

6) For jets from non-circular orifices that are symmetric with respect to the main flow direction, the effects of shape are significant in the region close to the injection plane, but farther downstream these geometries yield well mixed temperature distributions similar to those from equal ly-spaced, equival ent-area circular holes. 
7) Profiles for jets from 45-degree slanted slats shift laterally (z) as a function of momentum $f l u \%$ ratio and distance.

8) For opposed rows of jets, with the orifice centerlines in-line, the optimum ratio of orifice spacing to duct height is one-half of the optimum value for single-side injection at the same momentum ratio.

9) For opposed rows of jets, with the orifice centerlines staggered, the optimum ratio of orifice spacing to duct height is double the optimum value for single-side injection at the same momentum ratio.

10) At the same mamentum flux ratio, and with the same orifice spacing, double rows of in-line jets have temperature distributions similar to those from a single row of equal1y-spaced, equivalent-area circular orifices.

11) Jets from double rows of orifices of different size and spacing, or from double rows with orifices staggered, may be approximated by superimposing independent calculations of the two rows, but caution should be exercised using this model for very small offsets between the rows.

The PROFILES v2. 1 code used herein is quite capable of calculating flowfields which are physically unrealistic, and/or represent large extrapol ations from the test conditions in the data base on which the model is based. Some of these conditions are flagged in the program with warnings, but, of course, the user must always exercise judgement is using this or any other analytical tool.

\section{References}

1 Wal ker, R.E. and Kors, D.L., "Multiple Jet Study Final Report," Aerojet Liquid Rocket Co., Sacramento, Calif., NASA CR-121217, June 1973.

$=$ Hol deman, J.D., Walker, R.E., and Kors, D.L." "Mixing of Multiple Dilution Jets with a Hot Primary Airstream for Gas Turbine Combustors," AIAA Paper 73-1249, Nov. 1973 (NASA TM X-71426).

3 Kamotani, $Y$. and Greber, $I$, "Experiments on Confined Turbulent Jets in Cross Flow," Case Western Reserve Univ., Cleveland, Ohio, NASA CR-2392, Mar. 1974.

4 Walker, R.E. and Eberhardt, R.G.: "Multiple Jet Study Data Correlations." Aerojet Liquid Rocket Co., Sacramento, Calif., NASA CR-134795, Apr. 1975. s Holdeman, J.D. and Walker, R.E., "Mixing of a Row of Jets with a Confined Crossflow," AIAA Joumal, Vol. 15. No. 2, Feb. 1977 , pp. 243-249 (see al so ATAA Paper 76-48 (NASA TM-71821)).

- Cox, G.B. Jr., "Multiple Jet Correlations for Gas Turbine Engine Combustor Design," Journal of Engineering for Power, Val. 98, No. 2, Apr. 1976, pp. 265-273.

7 Cox, G.B. Jr., "An Analytical

Model for Predicting Exit Temperature Profile from Gas Turbine Engine Annular Combustors," AIAA Paper 75-1307, Sept. 1975.

- Khan, Z.A., McGuirk, J.J., and Whitelaw, J.H., "A Row of Jets in Crossflow," Fluid Dynamics of Jets with Application to U/STOL, AGARD-CP-30B, Paper No. 10, 1982.

$\rightarrow$ Hol deman, J.D., "Perspectives on the Mixing of a Row of Jets with a Confined Crossflow, " AIAA Paper 83-1200, June 1983 (NASA TM-83457).

10 Atkinson, K.N., Khan, Z.A., and Whitelaw, J.H., "Experimental Investigation of Opposed Jets Discharging Normally into a Cross-stream," Joumal of Fluid Mechanics, Vol. 115, 1982, pp. $493-504$.

11 Srinivasan, R., Berenfeld, A., and Mongia, H.C., "Dilution Jet Mixing Program Phase I Report," Garrett Turbine Engine Co., Phoenix, Ariz., Garrett 21-4302, Nov. 1982 (NASA CR-168031).

$1=$ Wittig, S.L.K., Elbahar, D.M.F., and Noll, B.E.: "Temperature Profile Development in Turbulent Mixing af Coolant Jets with a Confined Hot Cross-Flow," Journal of Engrineering for Gas Turbines and Power, Vol. 106, 1984, p. 193 (see also ASME Paper No. 83-GT-39).

23 Holdeman, J.D., Srinivasan, R., and Berenfeld, A., "Experiments in Dilution Jet Mixing," AIAA Joumnal, Vol. 22, No. 10, Oct. 1984, pp. 1436-1443 (see al so AIAA Paper 83-1201 (NASA TM (83457)).

14 Srinivasan, R., Coleman, E., Johnson, K., and Mongia, H.C., "Dilution Jet Mixing Program Phase II Report," Garrett Turbine Engine Co., Phoenix, Ariz., Garrett 21-4804, June 1984 (NASA CR-174624).

12 Hol deman, J.D., and Srinivasan, R., "Modeling of Dilution Jet Flowfields," Combustion Fundamentals Research, NASA CP-2309, Apr. 1984, pp. $175-187$ 
is Holdeman, J.D., Srinivasan,

R., Coleman, E.B., Meyers, G.D., and White, C.D., "Experiments in Dilution Jet Mixing Effects of Multiple Rows and Non-circular Orifices," AIAA Paper 85-1104, July 1985 (NASA TM-86996).

17 Srinivasan, R., Coleman, E., Meyers, G., and White, C., "Dilution Jet Mixing Phase III Report." Garrett Turbine Engine Company, Phoenix, Ariz., Garrett 21-5418, Sept. 1985 (NASA CR-174884).

1日 Hol deman, J.D., and Srinivasan, R., "Modeling of Dilution Jet Flowfields," Journal of Propulsion and Power, Vol . 2, No. 1, Jan./Feb. 1986, pp. 4-10 (see also AIAA Paper 94-1379 (NASA TM (83708)).

19 Bruce, T.W., Mongia, H.C.

Reynolds, R.S., "Combustor Design Criteria Validation," AiResearch Manufacturing Co. of Arizona, Phoenix, Ariz., Report 75-211682 (38), Mar. 1979 (ÚSARTL-TR-78-55A, $B$, and $C$ ).

20 C1 aus, R.W., "Analytical

Calculation of a Single Jet in Crossflow and Comparison with Experiment," AIAA Paper 83-0238, Jan. 1983 (NASA TM-83027).

21 Sturgess, Geoffrey $\mathrm{J}$. ,

"Aerothermal Modeling Phase I Final

Report," Pratt \& Whitney Aircraft, E.

Hartford, Conn., PWA-5907-19, May 1983 (NASA CR-168202).

za Srinivasan, R., Reynolds, R., Ba1 1, I., Berry, R., Johnson, K., and Mongia, H.C., "Aerothermal Modeling Program: Phase I Final Report - Vol. 2" Garrett Turbine Engine Co., Phoenix, Ariz., Garrett 21-4742-2, Aug- 1983 (NASA CR-168243).

23 Kenworthy, M.J., Correa,

S.M., and Burrus, D.L., "Aerothermal

Modei ing Phase I - Final Report: Volume I Model Assessment," General Electric

Company, Cincinnati, Ohio, NASA

CR-168296-vol-1, Nov. 1983.
Table 1. Range of Flow and Geometric Variables on which the empirical model is based.

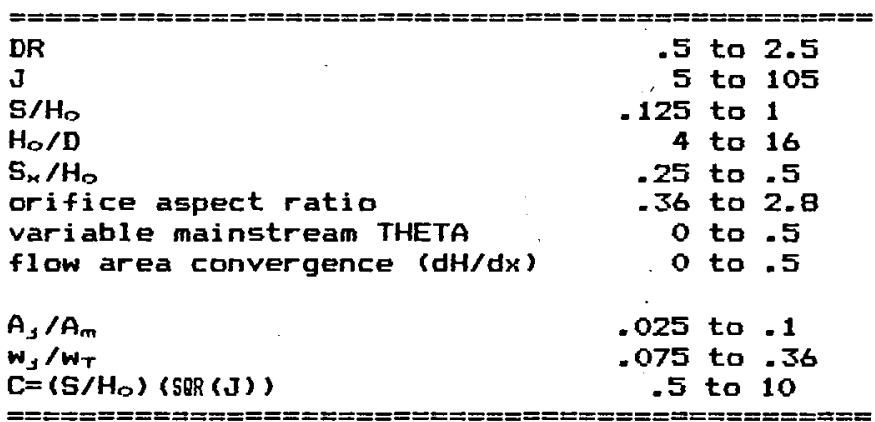

Table 2. Correspondence between empirical model calculations and experimental data in Refs. 11, 14, and 17 .

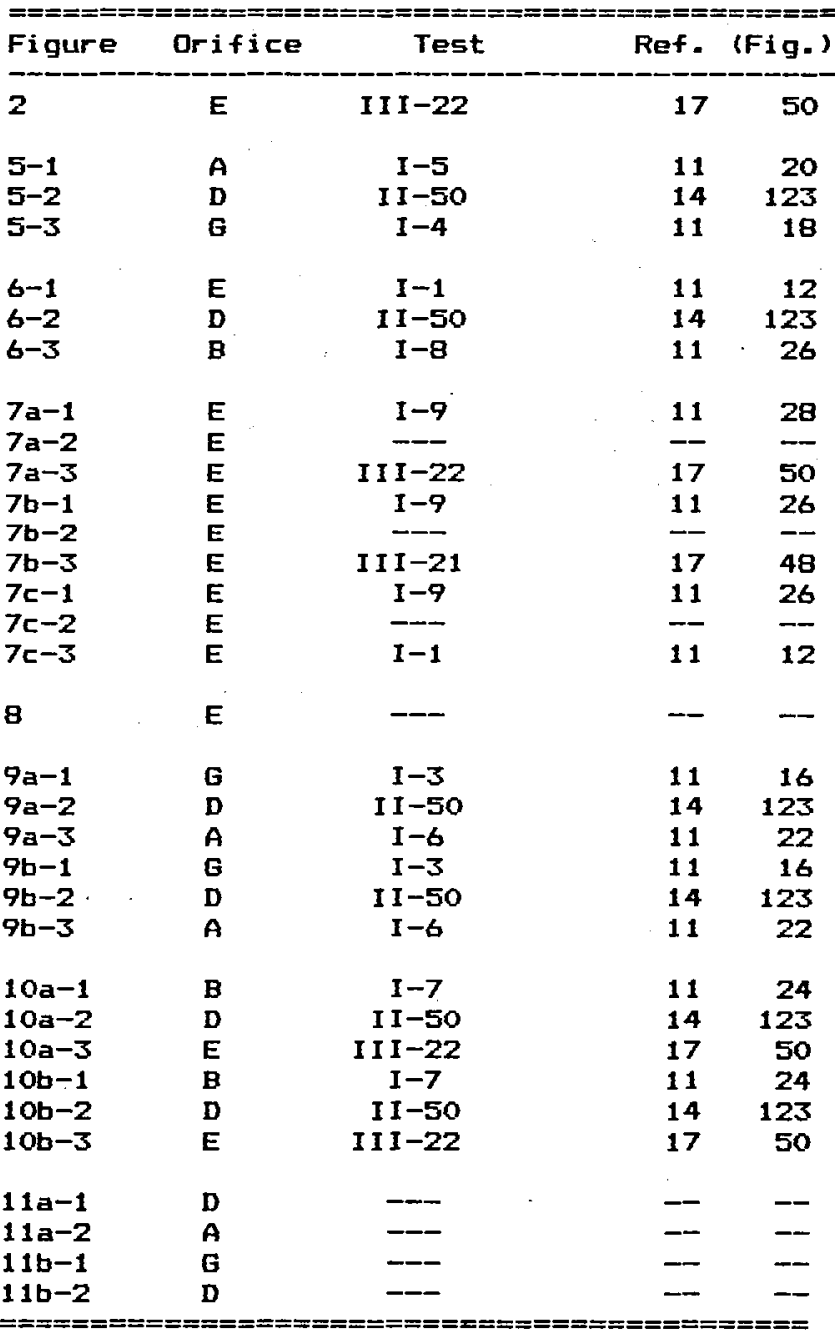


Table 2 (con't)

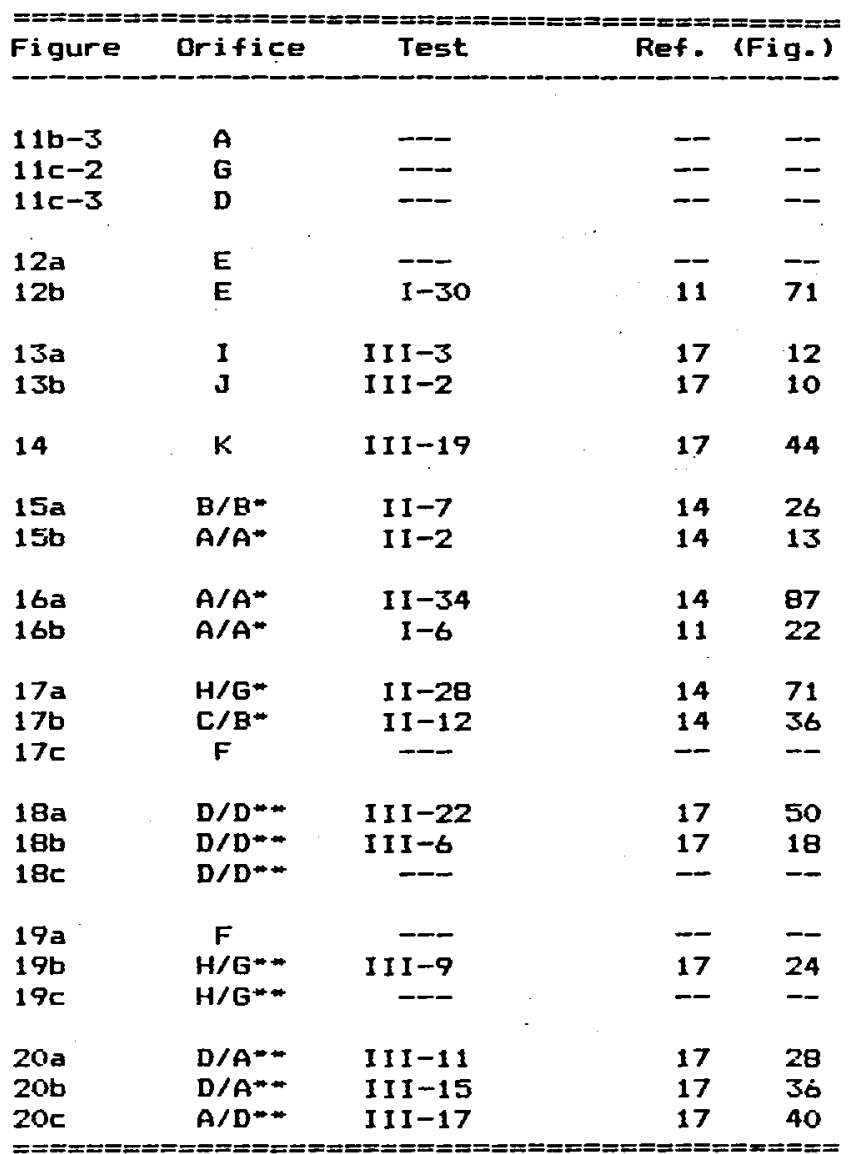

* top row/bottom row

* front row/rear row 


\section{Appendix - Correlation Equations}

Jet Thermal Centerline Trajectory

$\mathrm{Y}_{\mathrm{c}} / \mathrm{H}_{\operatorname{ma}}$

$=\left(a_{1}\right)(.3575)(J)=20(S / D)-14\left(H_{-q} / D\right)-.40\left(C_{a}\right)-100\left(X / H_{-q}\right) \cdot 17(\exp (-b))$

where $a_{2}=\min \left[\left(1+5 / H_{-a}\right), 2\right]$

and $\left.\quad b=(.091)\left(X / H_{-q}\right)=\left[\left(H_{-a} / S\right)-(J \cdot 0) / 3.5\right)\right]$

\section{Centerplane Maximum Temperature Difference Ratio}

THETA

$=$ THETAEg $+\left(1-\right.$ THETAEg $\left._{E}\right)\left[\left(a_{2}\right)(J)-.30\left(C_{a}\right) \cdot 0\left(H_{-a} / D\right)^{-1}\left(x / H_{-q}\right)^{-1}\right]^{*}$

where $f=1.15\left[\left(S / H_{-q}\right) /\left(1+S / H_{-q}\right)\right]=$

and THETAEB $=w_{J} / w_{T}$

\section{Centerplane Minimum Temperature Difference Ratios}

(THETA TI $\left.\left.^{+}\right)^{+}\right) /\left(\right.$THETA $\left._{e}\right)$

$=1-\exp \left(-c^{+}\right)$

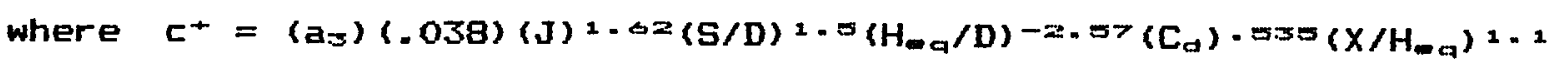

and $\quad a_{3}=1$

if $\left(Y_{c} / H_{-q}+W_{1} z^{+} / H_{-a}\right) \leq 1$

$\left.=\left(H_{0} / H_{-q}\right) \leq-6\right\rangle$

if $\left(Y_{c} / H_{-a}+W_{2 / 2}+/ H_{-a}\right)>1$

(THETA TIn $\left.^{-}\right) /\left(\right.$THETAE) $^{-}$

$=1-\exp \left(-c^{-}\right)$

where $c^{-}=(Q)(1.57)(J)^{-.5}(5 / D)-1.4\left(H_{-a} / D\right) \cdot 9\left(C_{a}\right) \cdot 2 E\left(x / H_{-a}\right) .9$

and $Q=1 \quad$ if $\left(Y_{c} / H_{m a}+W_{1 / 2}+/ H_{a q}\right) \leq 1$

$=\exp \left[(.22)\left(X / H_{-a}\right)=\left((J-0) / 5-5 / H_{-a}\right)\right]$ if $\left(Y_{c} / H_{-a}+W_{1}=+/ H_{a q}\right)>1$

Centerplane Half-Widths

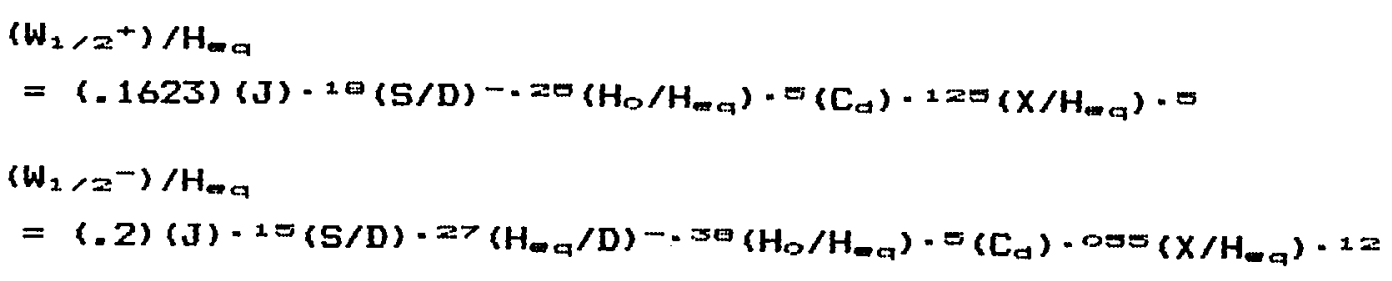




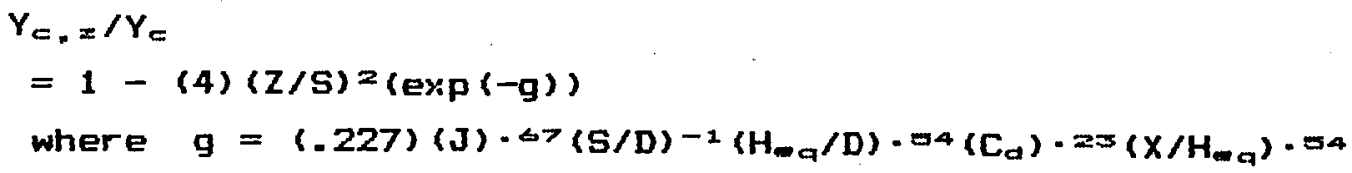

\section{Qff-centerplane Maximum Temperature Difference Ratio}

(THETA,$z) /$ THETA

$$
\begin{aligned}
& =1-(4)(Z / S)=(\exp (-d))
\end{aligned}
$$

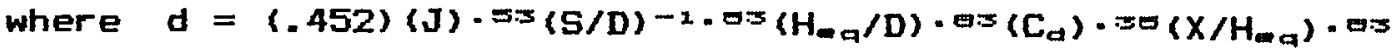

\section{Qff-centerplane Minimum Temperature Difference Ratios}

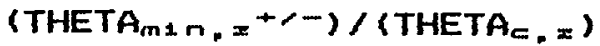

$=\left(T_{H E T A} A_{m+1}+-\right) /\left(T_{H E T A_{C}}\right)$

\section{Qff-centerplane Half-widths}

$$
\begin{aligned}
& \left(w_{1} / z_{x}+r-\right) / H_{-a} \\
& =\left(w_{1}, 2^{+} /-\right) / H_{-a}
\end{aligned}
$$

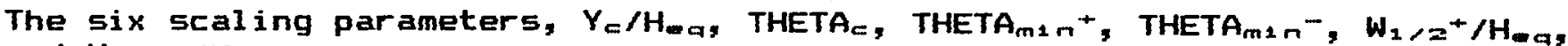
and $w_{1} z^{-} / H_{m}$, are used in Eq. (2) to define the vertical profile at any $x, z$ location in the flow. For al1 except the case of opposed rows of jets with centerlines in-line, $H_{-a}$ in the correlation equations is equal to $H_{o}$, the height of the duct at the injection location.

\section{Non-isothermal mainstream}

Double (axially staged) rows of Jets

Opposed Rows of Jets with Centerlines Staggered

It was shown in Ref. 18 that these flows can be satisfactorily modeled by superimposing independent calculations of the separate elements. This is accomplished as follows:

THETA $=\left[\right.$ THETA $_{1}+$ THETA $_{2}-(2)\left(\right.$ THETA $\left._{1}\right)\left(\right.$ THETA $\left.\left._{2}\right)\right] /\left[1-\left(\right.\right.$ THETA $\left._{2}\right)\left(\right.$ THETA $\left.\left._{2}\right)\right]$

Note that THETA = THETA ${ }_{1}$ at any location where THETA $=0$ (and THETA $=$ THETA $_{2}$ if THETA $_{1}=0$ ); and that THETA $\leq 1$ (provided that THETA ${ }_{1}$ and THETA 2 are each $\leq 1)$. Also, for the completely mixed case THETAEa is equal to the ratio of the total jet flow to the mainstream flow as required. 
It was observed in Ref. 3 that the flowfield downstream of opposed jets was similar to that downstream of a single jet injected toward an opposite wall at half the distance between the jets. This is confirmed by the experimental results in Ref. 14 also. Thus for the symmetric case, $H_{m a}=\left(H_{0}\right) / 2$.

In general, these flows can be modeled by calculating an effective duct height as proposed in Ref. 12, namely;

$$
\begin{aligned}
{\left[H_{\text {ea }}\right]_{\text {top }}=\left(H_{0}\right) } & \left(\left[\left(A_{J} / A_{m}\right)(J \cdot \nabla)\right]_{\text {top }}\right) / \\
& \left(\left[\left(A_{J} / A_{m}\right)(J \cdot \sigma)\right]_{\text {top }}+\left[\left(A_{J} / A_{m}\right)(J \cdot \sigma)\right]_{\text {bottom }}\right)
\end{aligned}
$$

and

$\left[H_{\text {ma }}\right]_{\text {bottom }}=H_{0}-\left[H_{a q}\right]_{t a p}$

\section{Flow Area Converqence}

This case is modeled by assuming that the accelerating mainstream will act to decrease the effective momentum flux ratio as the flow proceedsi downstream, thus:

$J(x)=(J)\left[H(x) / H_{0}\right]=$

Note that the the trajectory and the jet half-widths are calculated in terms of the duct height at the injection location, so must be scaled by the inverse of the convergence rate, $H_{o} / H(x)$, to give profiles in terms of the local duct height.

\section{Orifice Aspect Ratio}

It was observed in Ref. 17 that bluff slots resulted in slightly less jet penetration and more two-dimensional profiles than circular holes, and that streamlined slots resulted in slightly greater jet penetration and more three-dimensional profiles.

This effect is modeled by using the ratio of the orifice spacing to the orifice width, $S / W$, in lieu of $S / D$ in the correlation equations.

For rectangular orifices with circular ends;

$S / W=(S / D)[1+(4 / p i)(A R-1)] \cdot=$

$$
\text { if } A R>1
$$

and

$S / W=(S / D)[1+(4 / p i)(1 / A R-1)] \cdot=/ A R$

where $\quad A R=W / L$

\section{S1 anted 51 ats}

Two effects were noted in the experimental results for slanted slots, namely that the centerplanes shifted laterally with increasing downstream distance, and the axes of the kidney-shaped temperature contours were inclined with respect to the injection direction. The former is modeled as a function of momentum flux ratio and downstream distance as:

$d z / 5=\sin [(p i / 2)(a)]$

where $a=\min \left[1,\left(x / H_{-q}\right)\{J / 26.4) \cdot=0\right]$

The rotation effect observed in the experimental data is not modeled. 


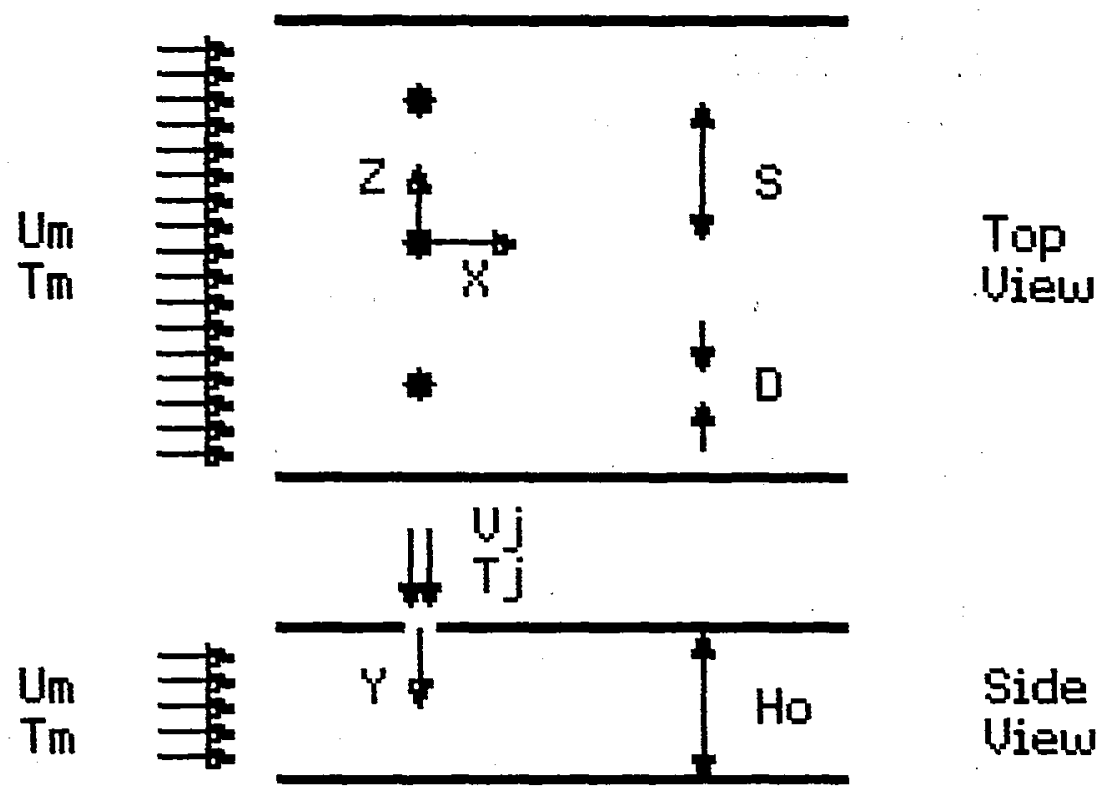

Figure 1. Flow schematic for the mixing of a row of jets. with a confined crossflow
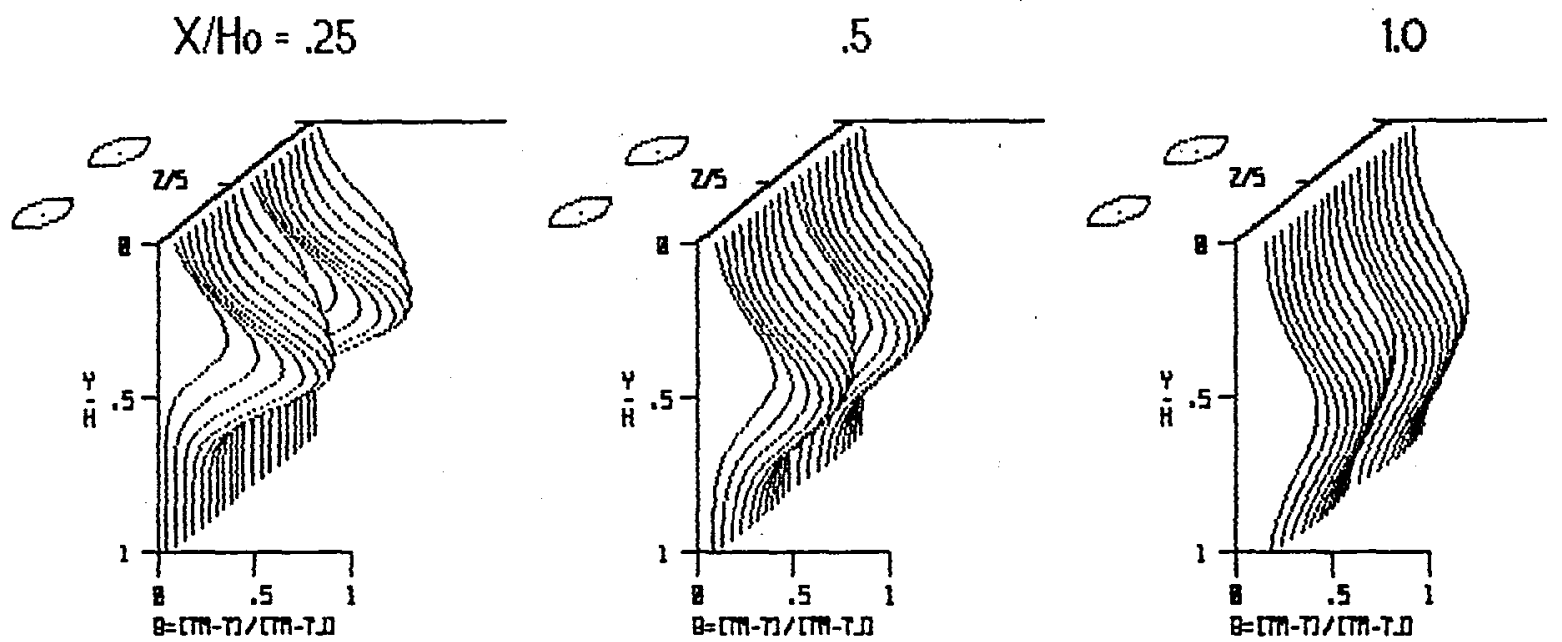

Figure 2. Temperature profiles with increasing downstream distance $(\mathrm{S} / \mathrm{Ho}=.5 ; \mathrm{Ho} / \mathrm{D}=4 ; \mathrm{J}=26.4 ; \mathrm{DR}=2.2 ; \mathrm{Cd}=.64)$. 

S/Ho Ho/D
A
.258
00000000
B $\quad .5$
8
$0 \quad 0$
$\mathrm{O}$
$\mathrm{O}$
C $\quad .5$
83
0
$\mathrm{O}$
O C
$\begin{array}{ll}\text { D } & .5 \\ \text { E } & .5\end{array}$
5.66
$0 \quad 0$
G
I
4
0<smiles>[O]</smiles><smiles>C1CCCCCC1</smiles><smiles>C1CCCCCC1</smiles>
F $\quad .5$
43
0
0
0
C
G 1
4
()
(1)
H 14
0
c
I $\quad .5$
4

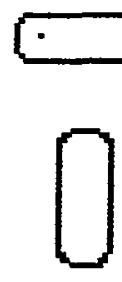
0
0
$\square$
$J \quad .5$
4
K .5

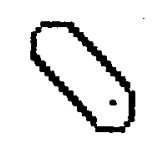

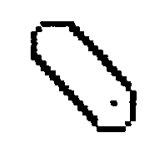
$\mathrm{O}$
0
4

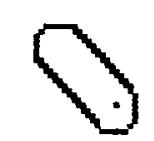

Figure 3. Orifice Configurations 


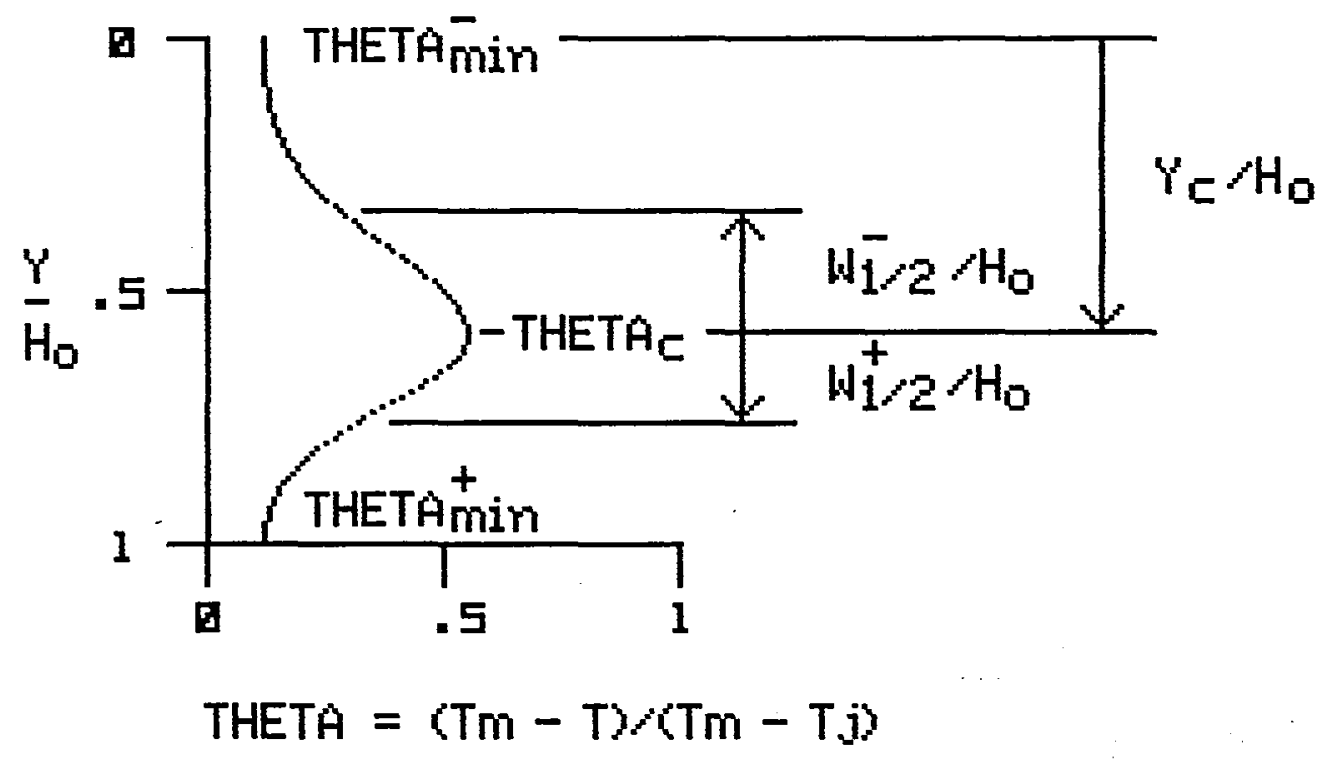

Figure 4. Typical vertical temperature
profile showing scaling
parameters in empirical model
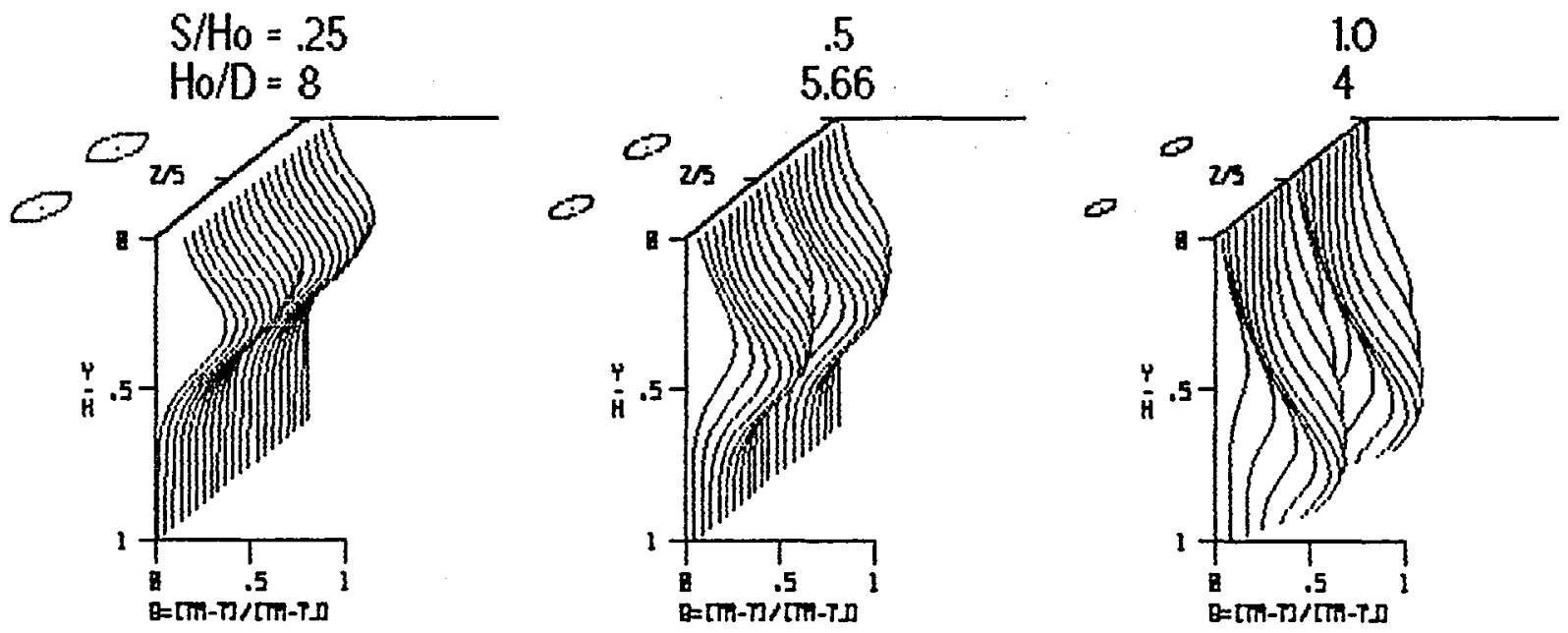

Figure 5. Temperature profiles with variation in orifice size and spacing at constant total area $(\mathrm{J}=26.4 ; \mathrm{X} / \mathrm{Ho}=.5 ; \mathrm{DR}=2.2 ; \mathrm{Cd}=.64)$ 

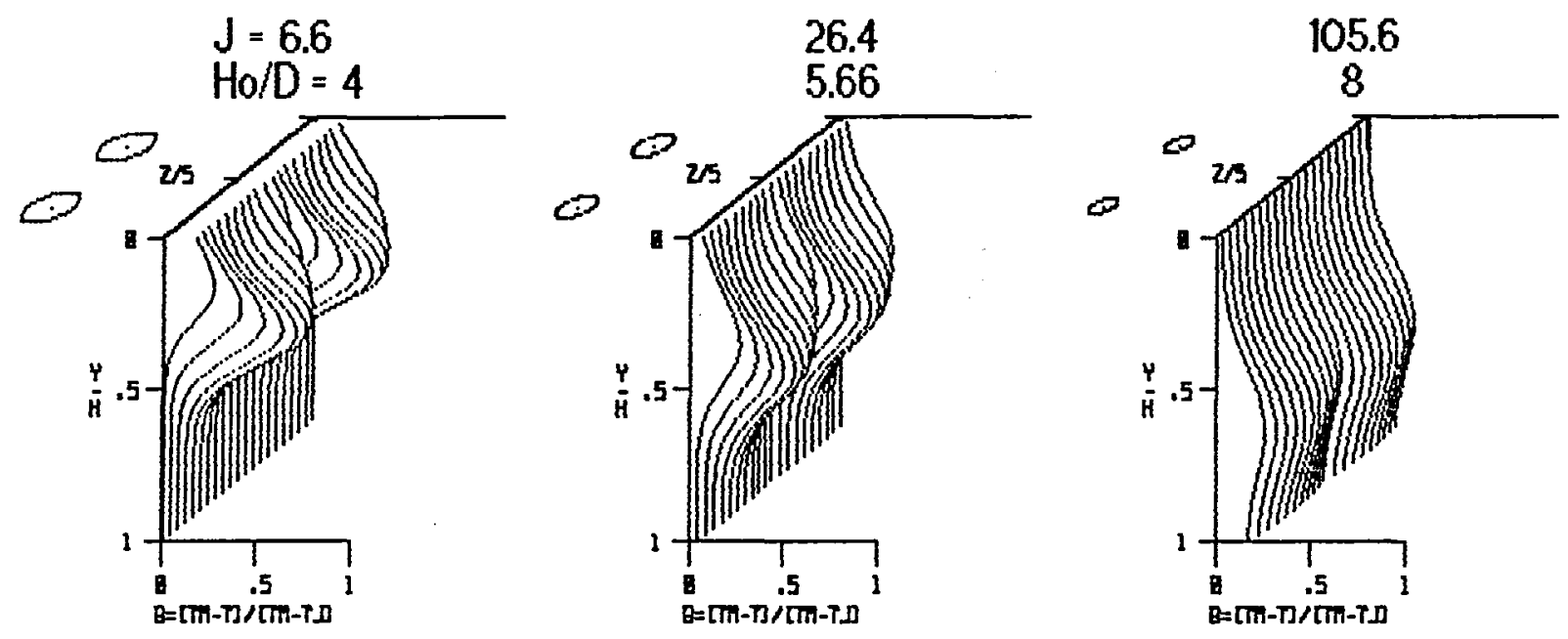

Figure 6. Temperature profiles with variation in momentum flux ratio $\left(\mathrm{S} / \mathrm{Ho}_{0}=.5 ; \mathrm{X} / \mathrm{Ho}_{\mathrm{O}}=.5 ; \mathrm{DR}=2.2 ; \mathrm{Cd}=.64\right)$. 

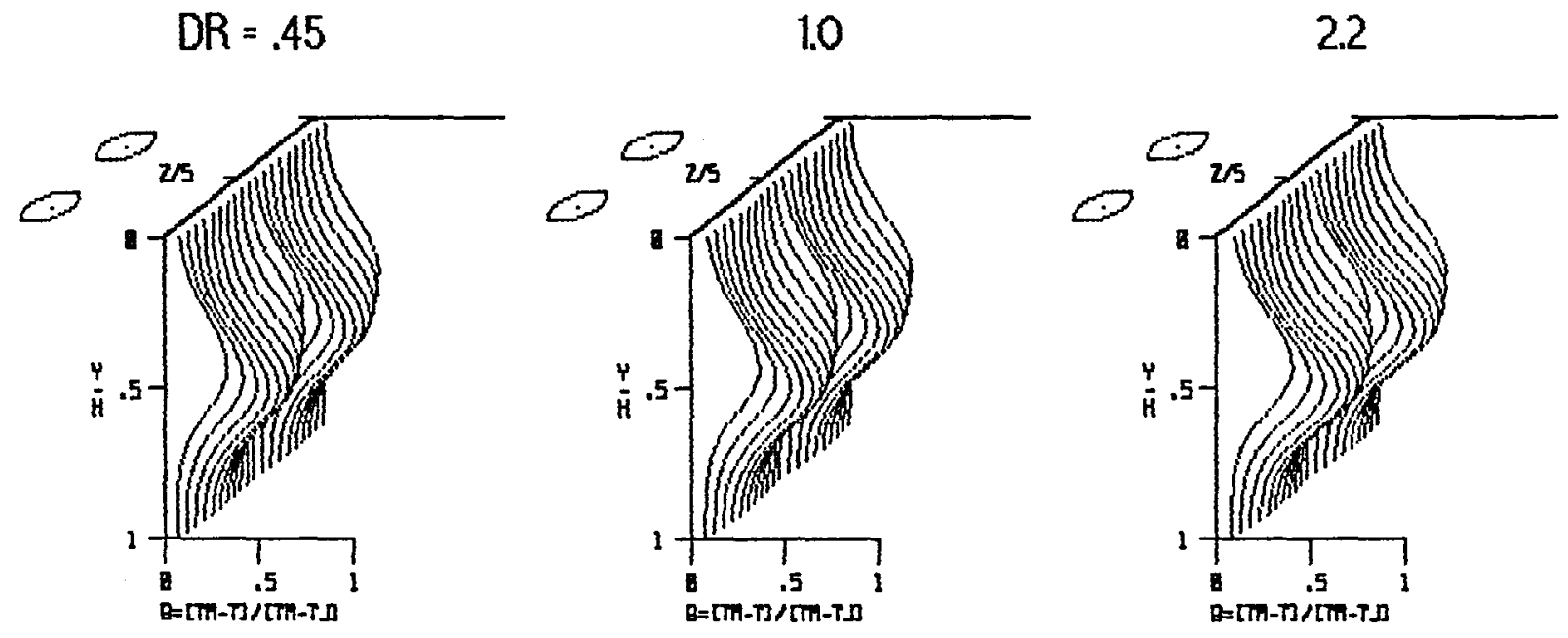

a) constant momentum flux ratio $=26.4$
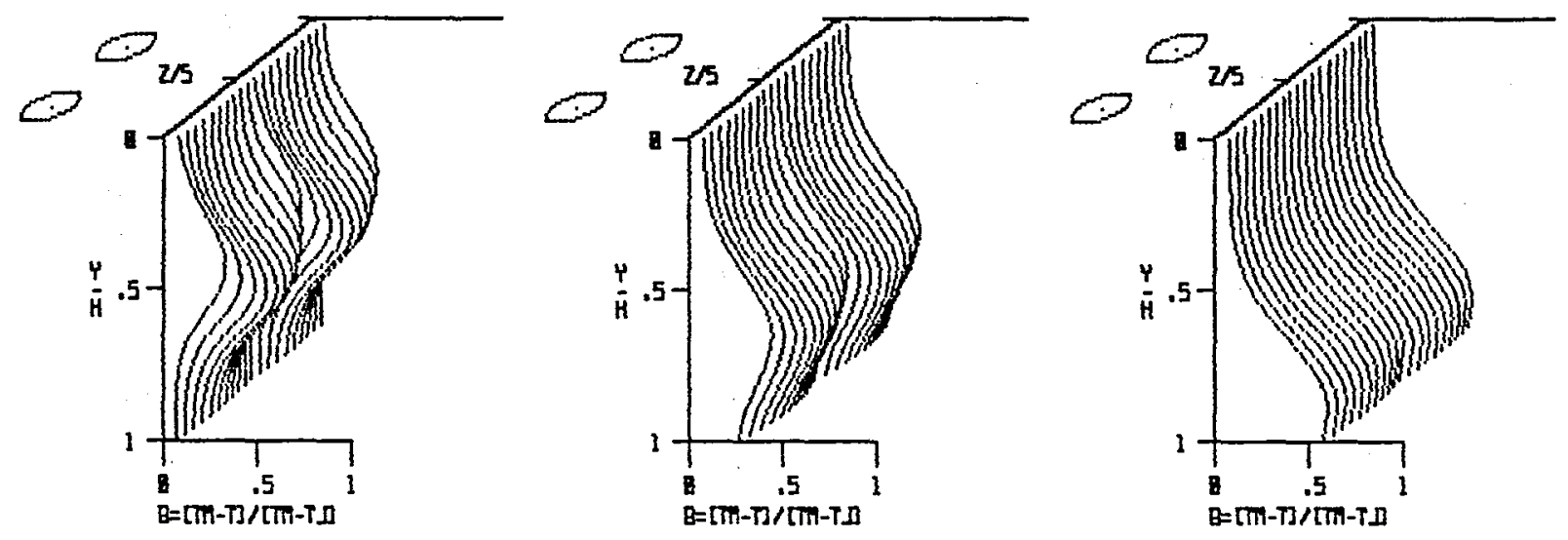

b) constant velocity ratio $=7.66$
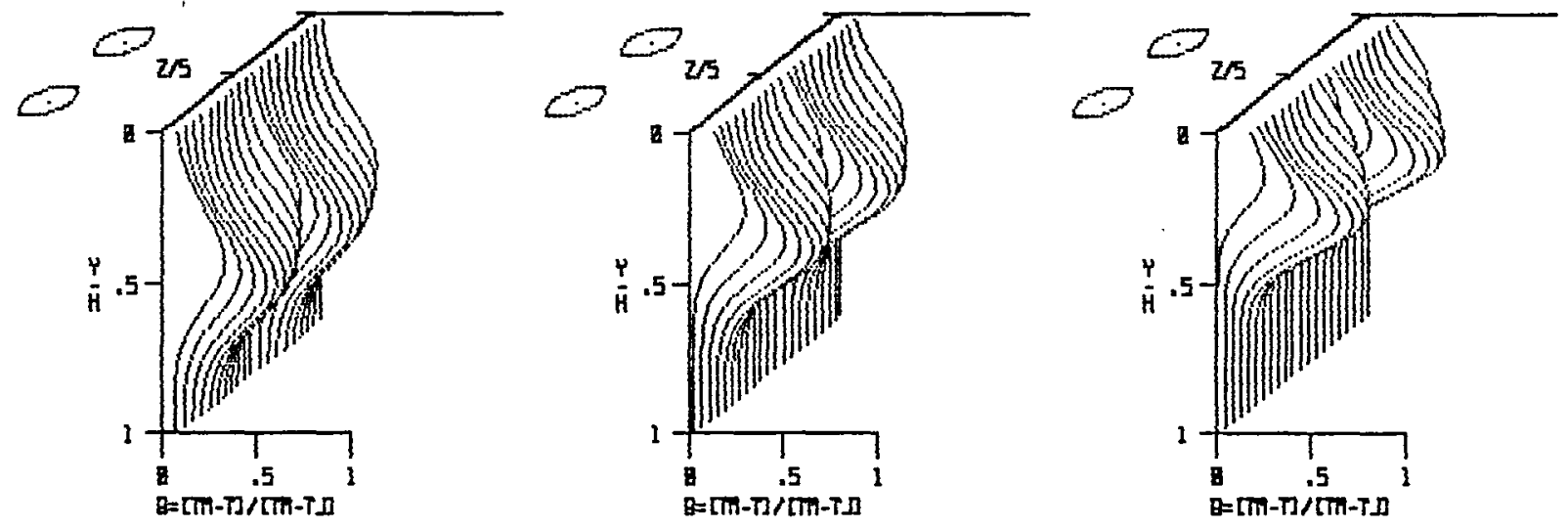

c) constant mass flux ratio $=3.45$

Figure 7. Temperature profiles with variation in density ratio $\left(\mathrm{S} / \mathrm{Ho}_{0}=.5 ; \mathrm{Ho}_{\mathrm{O}} / \mathrm{D}=4 ; \mathrm{X} / \mathrm{Ho}_{0}=.5 ; \mathrm{Cd}=.64\right)$. 

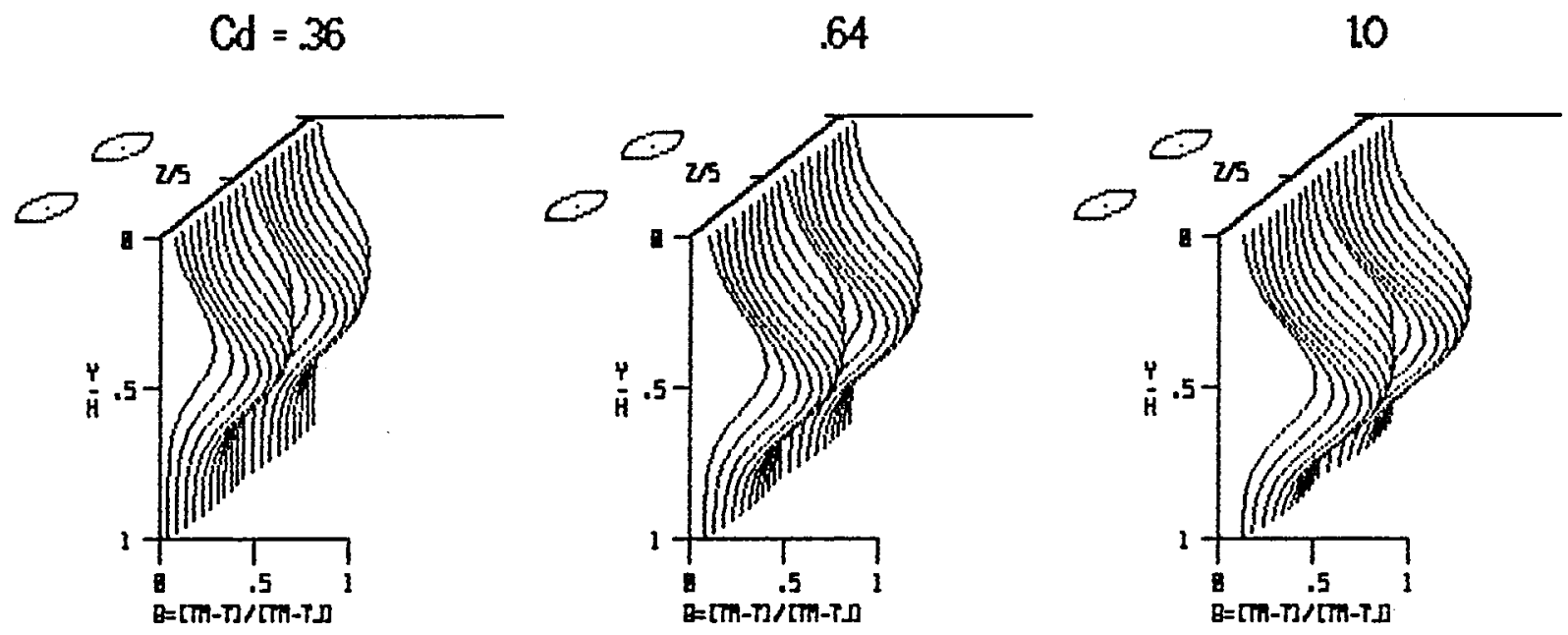

Figure 8. Temperature profiles with variation of orifice discharge coefficient $\left(\mathrm{S} / \mathrm{Ho}_{\mathrm{O}}=.5 ; \mathrm{Ho} / \mathrm{D}=4 ; \mathrm{J}=26.4 ; \mathrm{DR}=2.2 ; \mathrm{X} / \mathrm{Ho}_{0}=.5\right)$ 

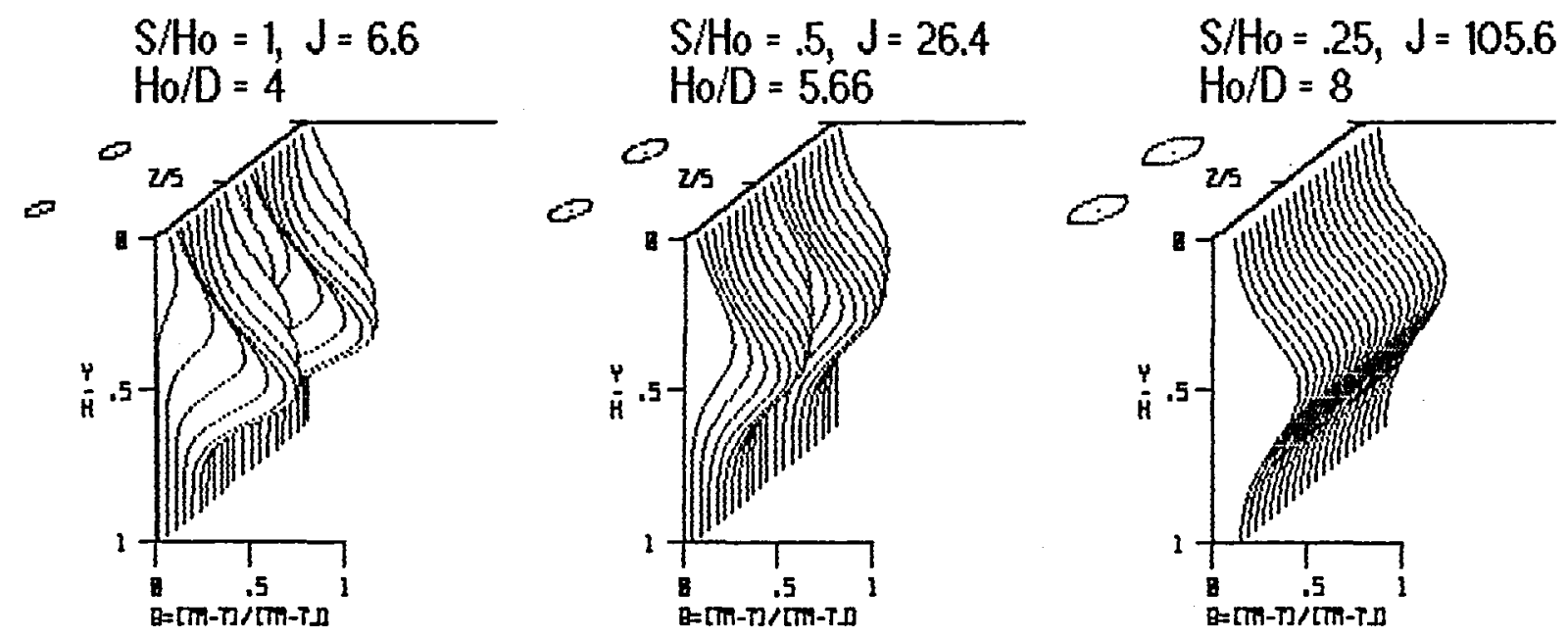

a) $\mathrm{X} / \mathrm{H}_{0}=.5$
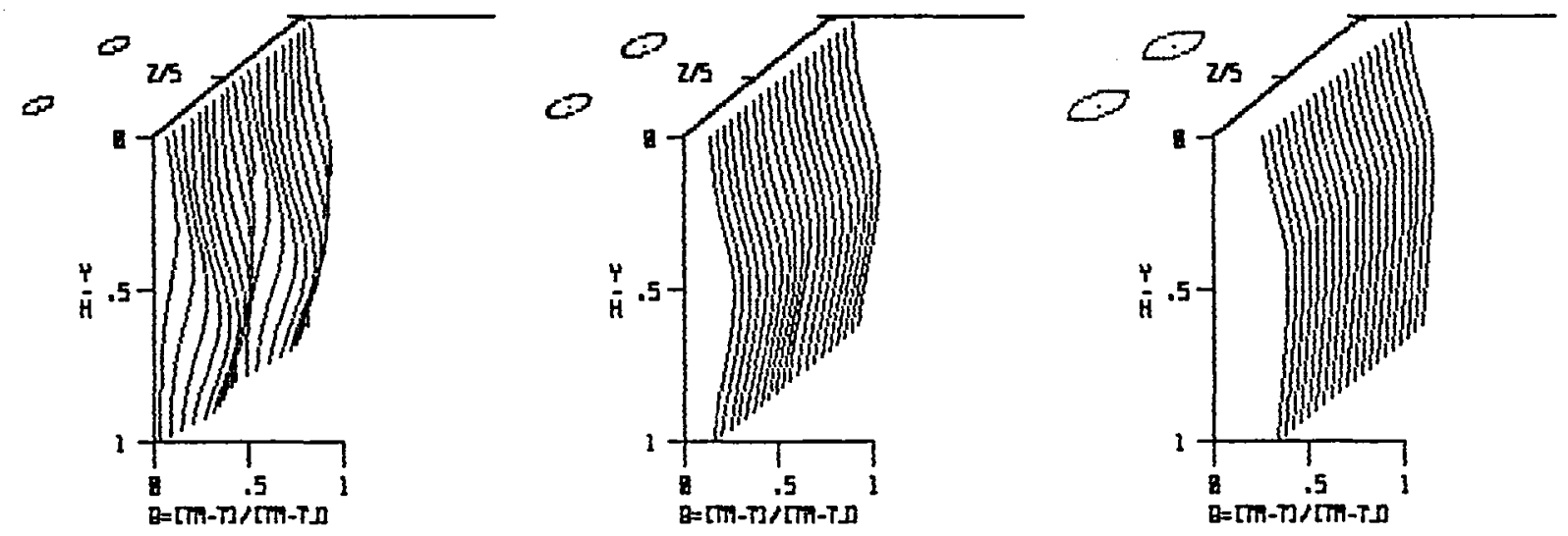

b) $\mathrm{X} / \mathrm{H}_{0}=2$

Figure 9. Temperature profiles with coupled orifice spacing \& momentum flux ratio; $\mathrm{C}=2.57(\mathrm{DR}=2.2 ; \mathrm{Cd}=.64)$. 

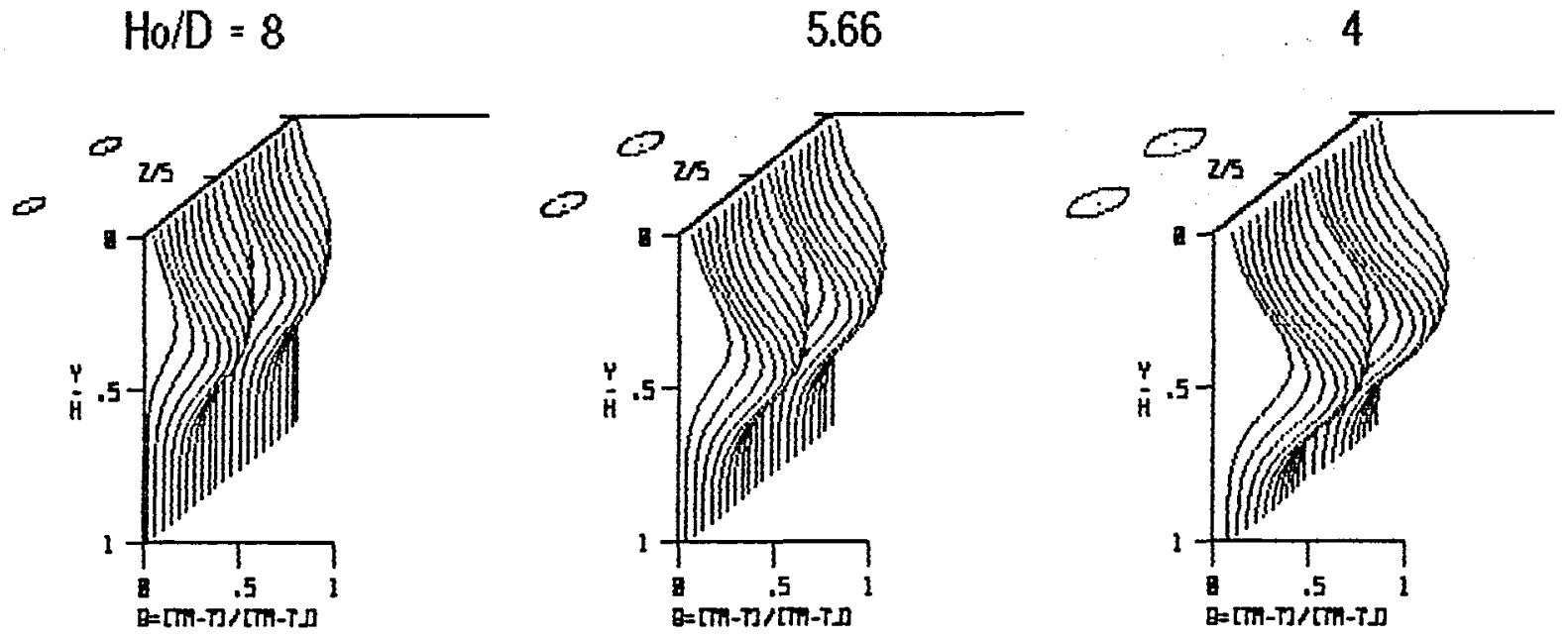

a) $\mathrm{X} / \mathrm{H}_{0}=.5$
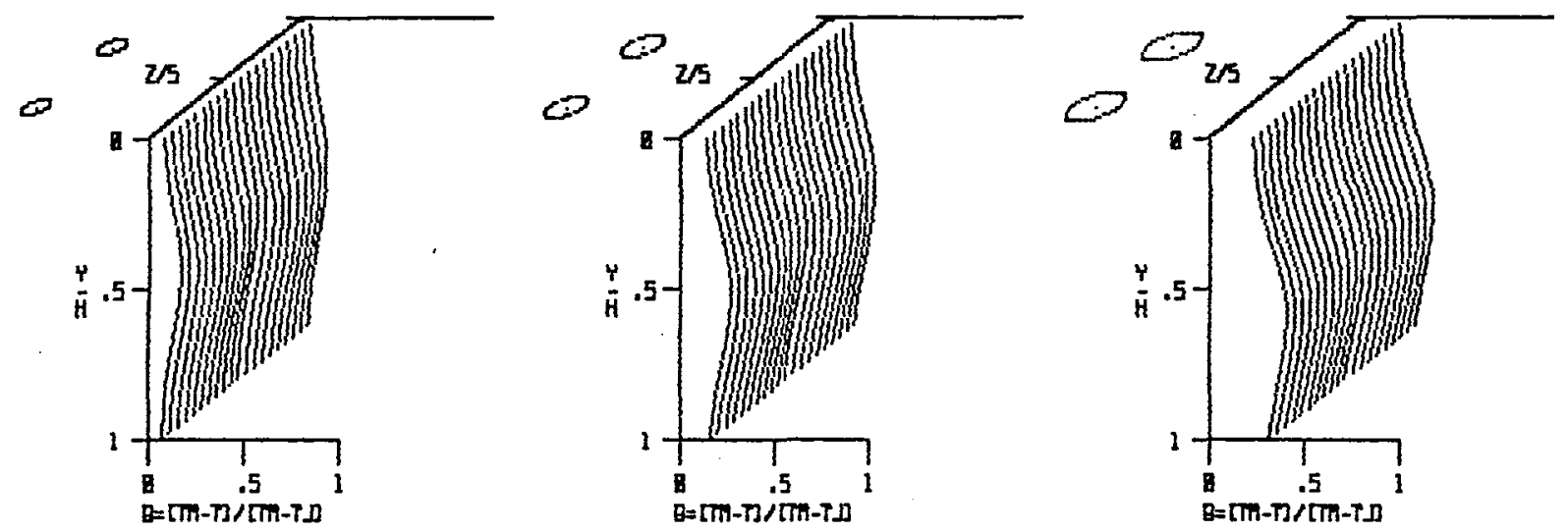

b) $X / H_{0}=2$

Figure 10. Temperature profiles with variation in orifice size at constant spacing $\left(S / H_{0}=.5 ; \mathrm{J}=26.4 ; \mathrm{DR}=2.2 ; \mathrm{Cd}=.64\right)$. 

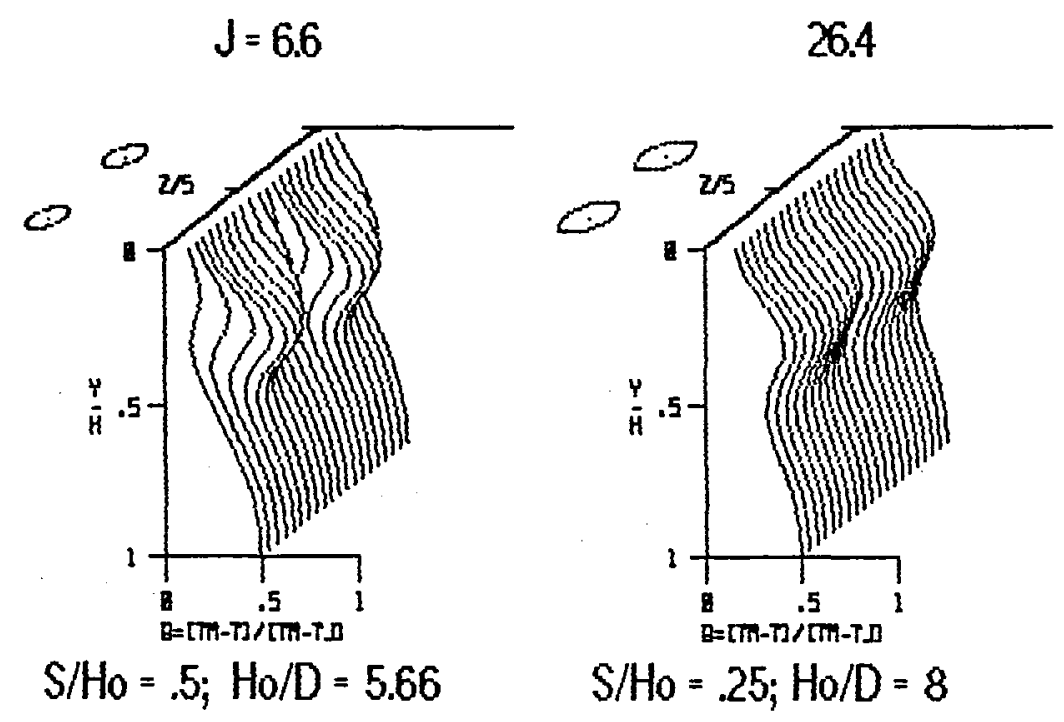

105.6

$\mathrm{S} / \mathrm{Ho}_{\mathrm{O}}=.5 ; \mathrm{Ho} / \mathrm{D}=5.66 \quad \mathrm{~S} / \mathrm{Ho}_{\mathrm{O}}=.25 ; \mathrm{Ho} / \mathrm{D}=8$

a) top hot; $\mathrm{C}=1.28$
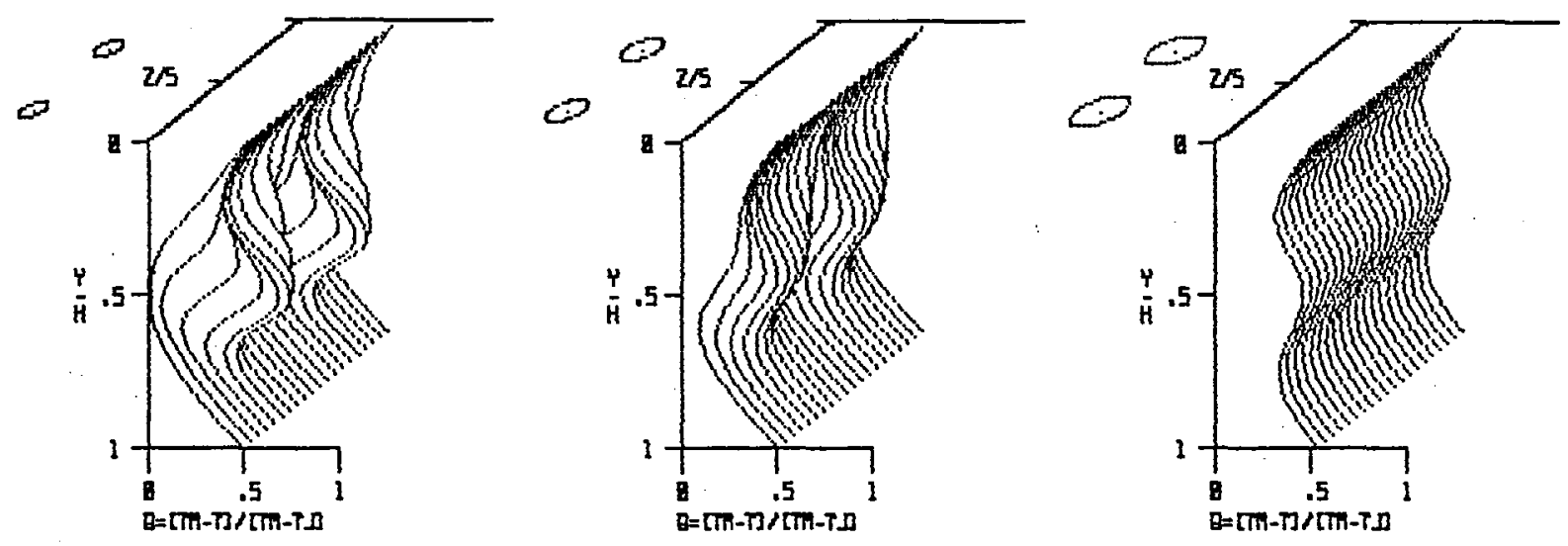

$\mathrm{S} / \mathrm{Ho}_{\mathrm{O}}=\mathrm{j} ; \mathrm{Ho}_{\mathrm{O}} / \mathrm{D}=4$

b) symmetric; $\mathrm{C}=2.57$

$S / H_{0}=.5 ; H_{0} / \mathrm{D}=5.66$

$S / H_{0}=.25 ; H o / D=8$

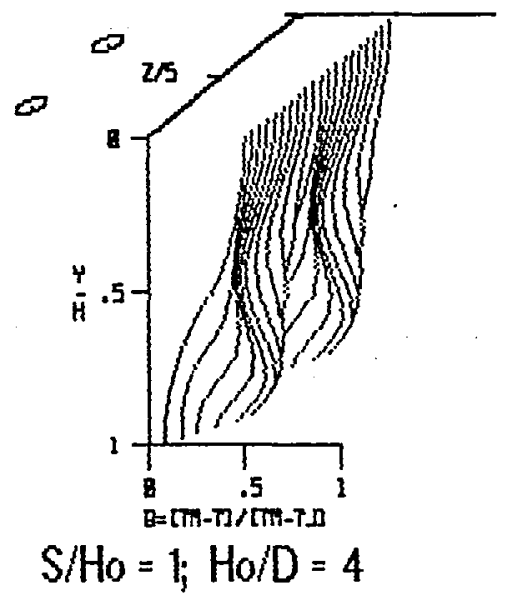

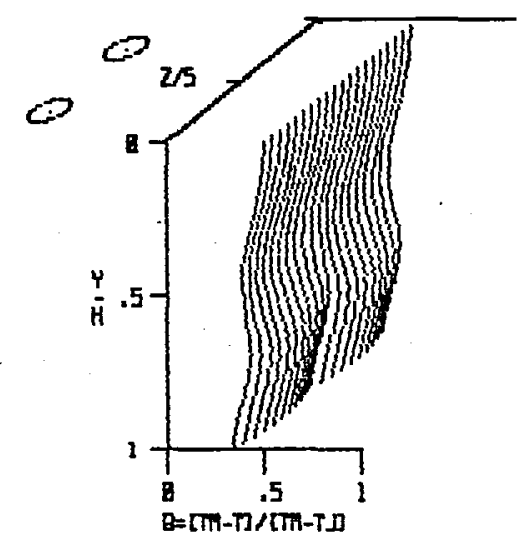

$S / H_{0}=.5 ; H_{0}=5.66$

c) top cold; $C=5.14$

Figure 11. Temperature profiles with non-isothermal mainstream $(\mathrm{X} / \mathrm{Ho}=.5 ; \mathrm{DR}=2.2 ; \mathrm{Cd}=.64)$. 

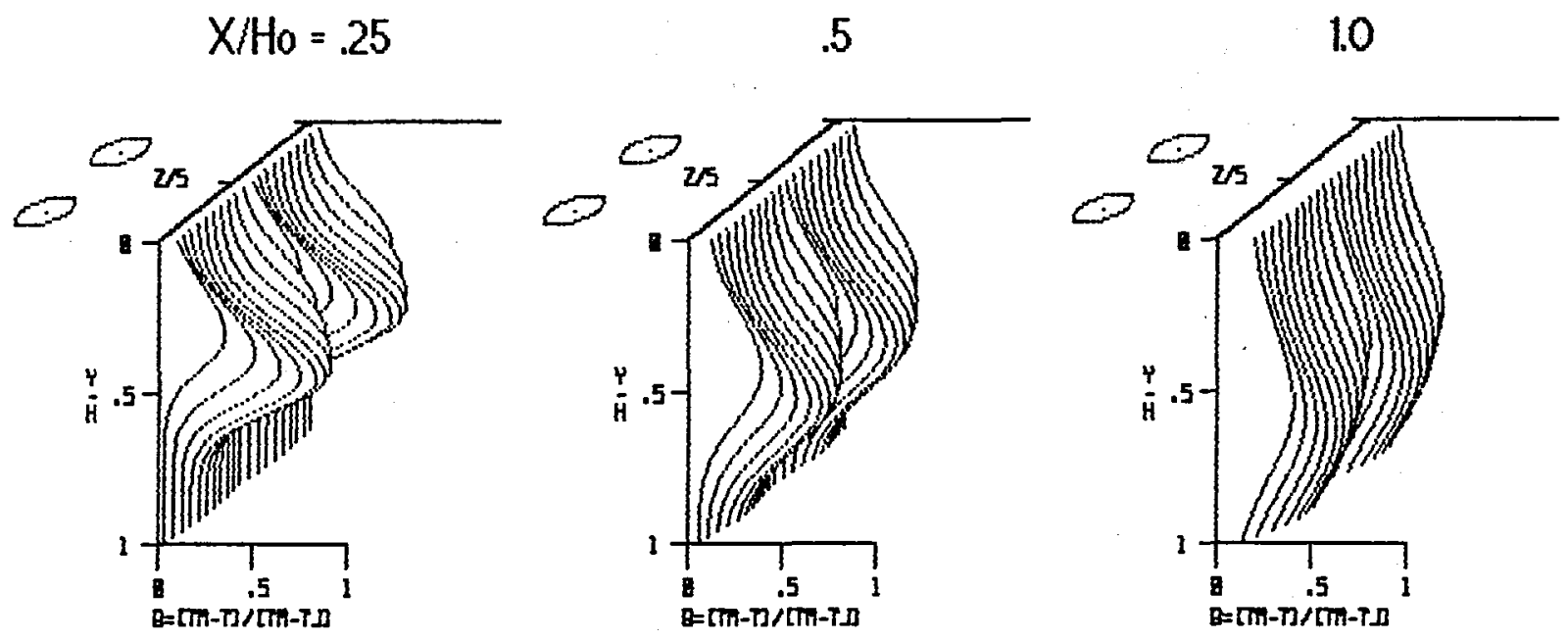

a) convergence $=.25 \mathrm{~cm} / \mathrm{cm}$
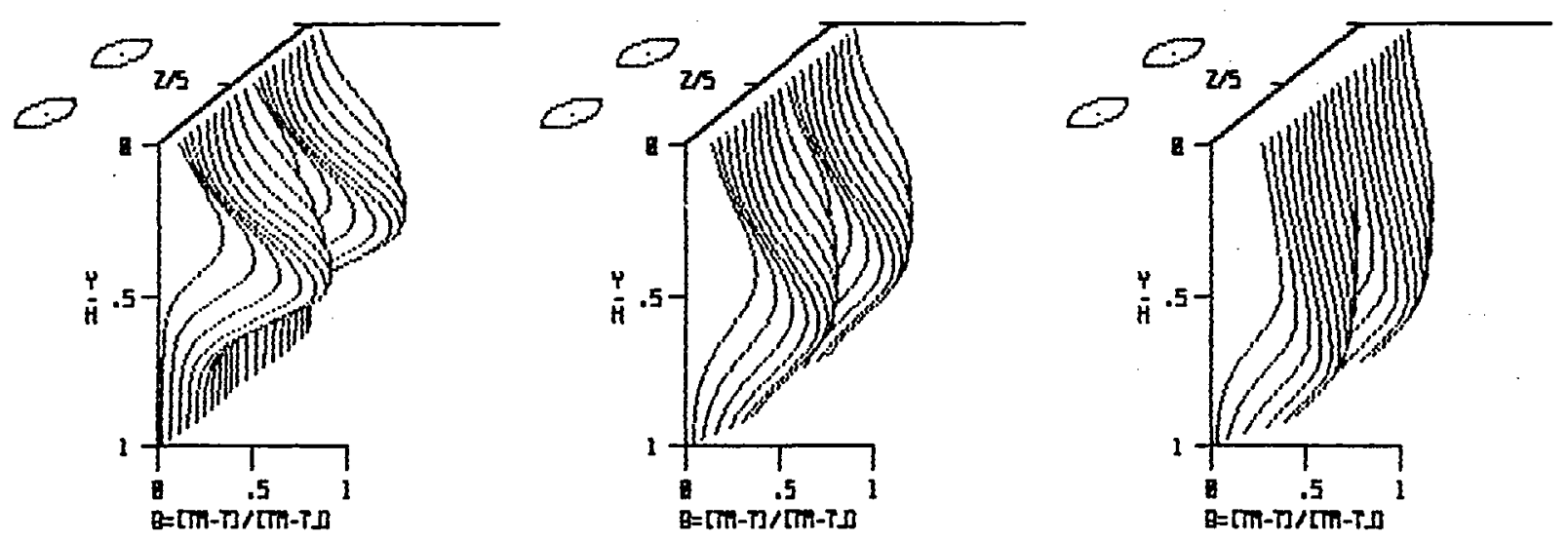

b) convergence $=.5 \mathrm{~cm} / \mathrm{cm}$

Figure 12. Temperature profiles with flow area convergence $\left(\mathrm{S} / \mathrm{Ho}_{\mathrm{O}}=.5 ; \mathrm{Ho} / \mathrm{D}=4 ; \mathrm{J}=26.4 ; \mathrm{DR}=2.2 ; \mathrm{Cd}=.64\right)$. 

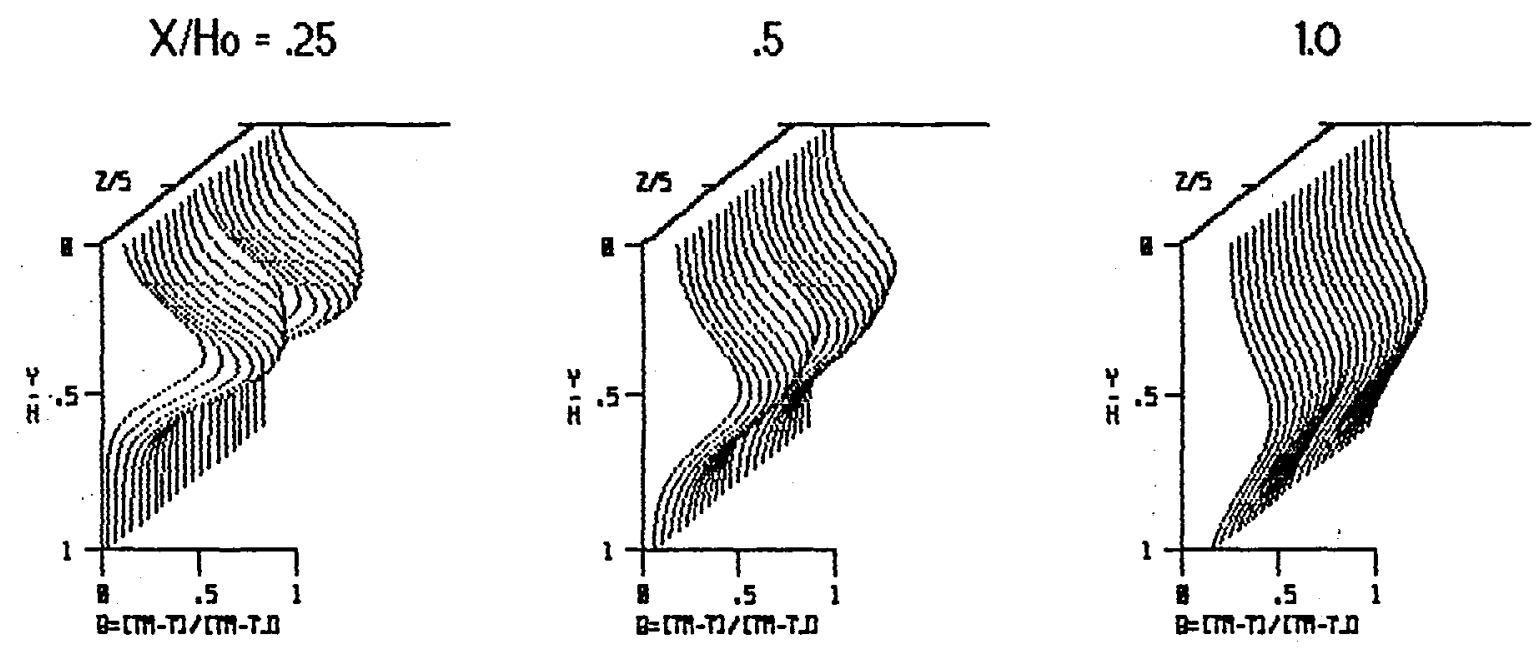

a) bluff slots; aspect ratio $=2.85$
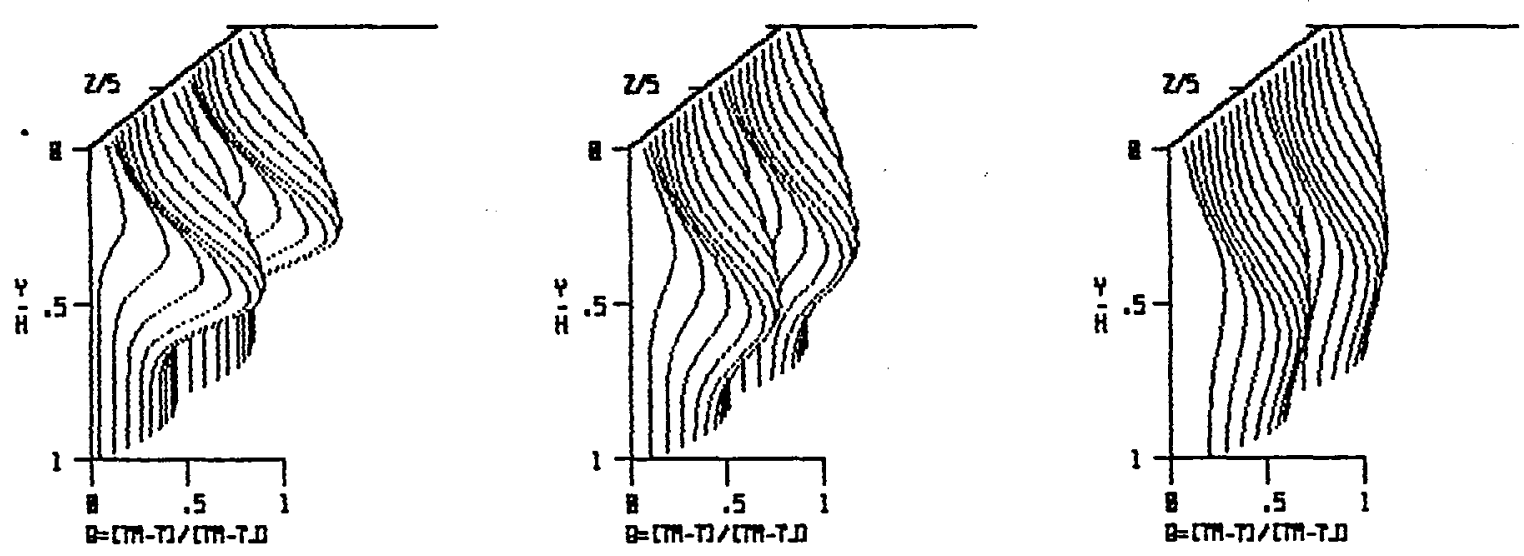

b) streamlined slots; aspect ratio $=.35$

Figure 13. Temperature profiles for bluff and streamlined slots $(\mathrm{S} / \mathrm{Ho}=.5 ; \mathrm{Ho} / \mathrm{D}=4 ; \mathrm{J}=26.4 ; \mathrm{DR}=2.2 ; \mathrm{Cd}=.64)$. 

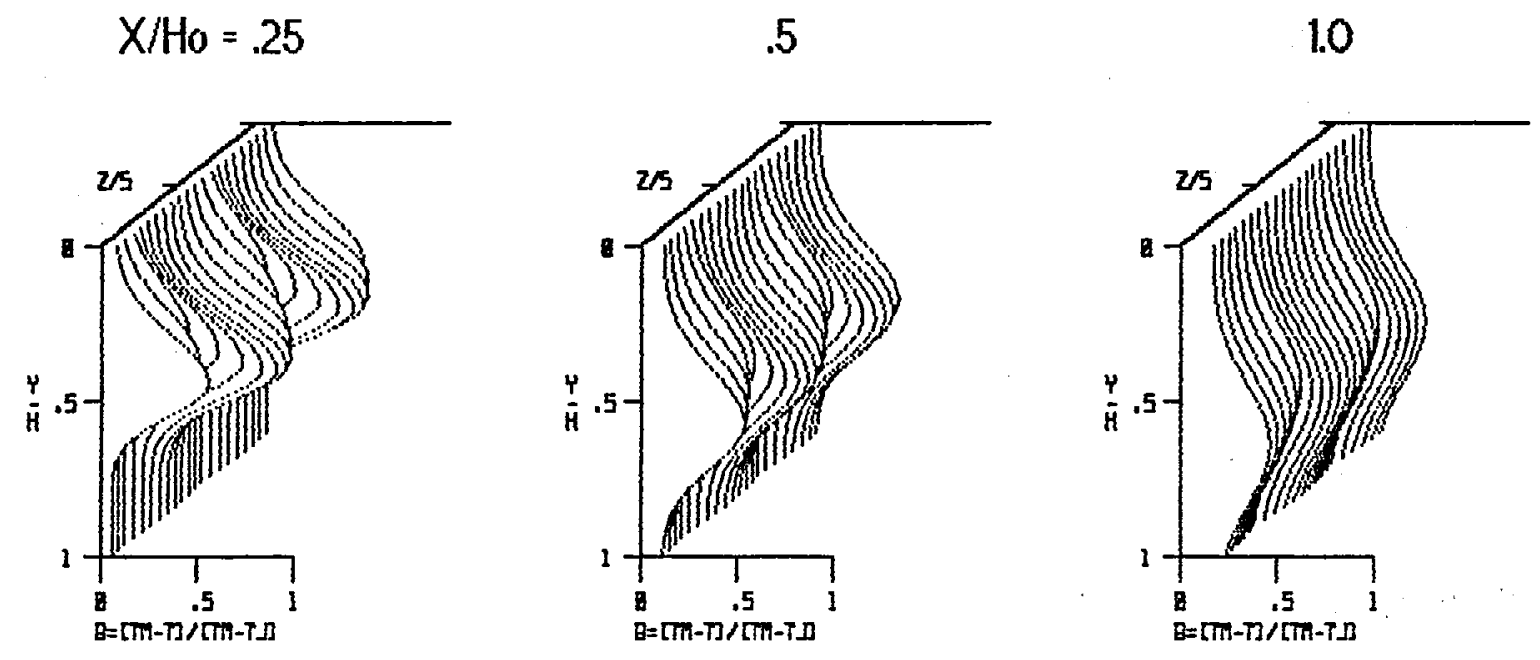

Figure 14. Temperature profiles for slanted slots $(\mathrm{S} / \mathrm{Ho}=.5 ; \mathrm{Ho} / \mathrm{D}=4 ; \mathrm{J}=26.4 ; \mathrm{DR}=2.2 ; \mathrm{Cd}=.64)$. 

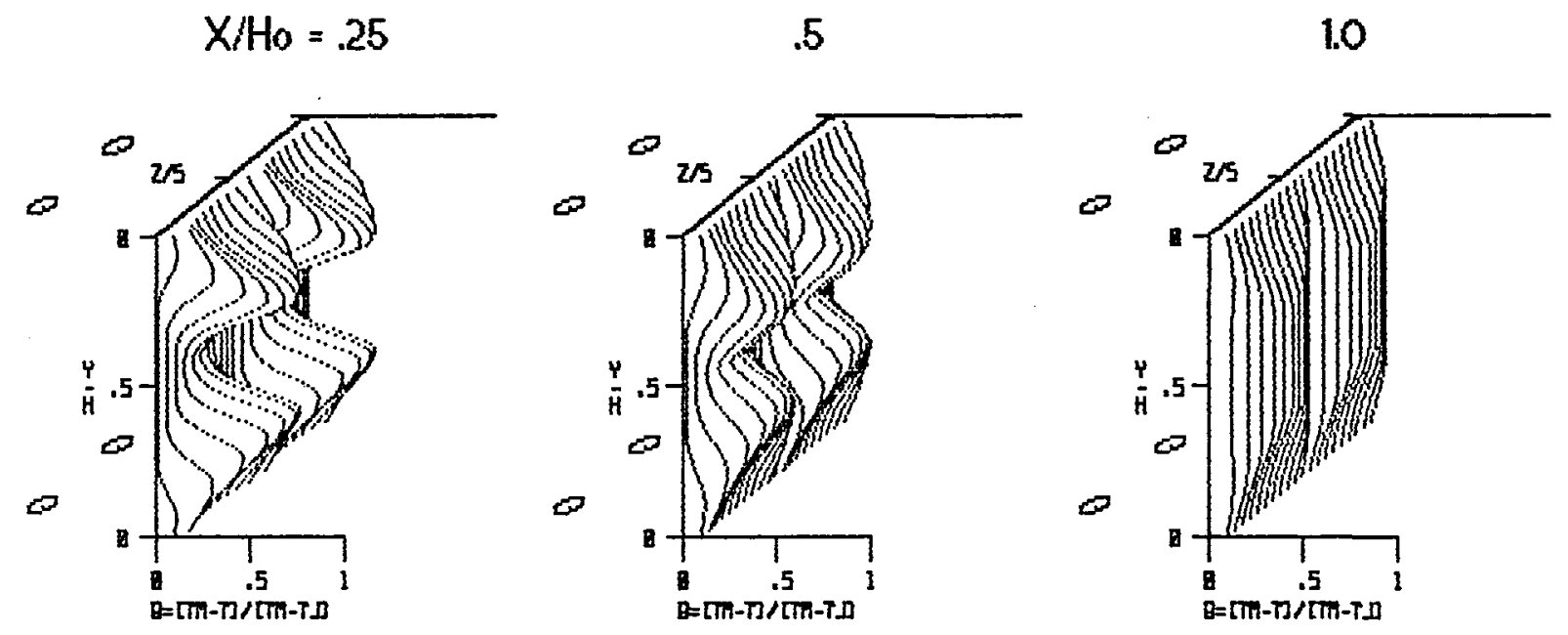

a) $\mathrm{S} / \mathrm{H}_{0}=.5 ; \mathrm{J}=6.6$
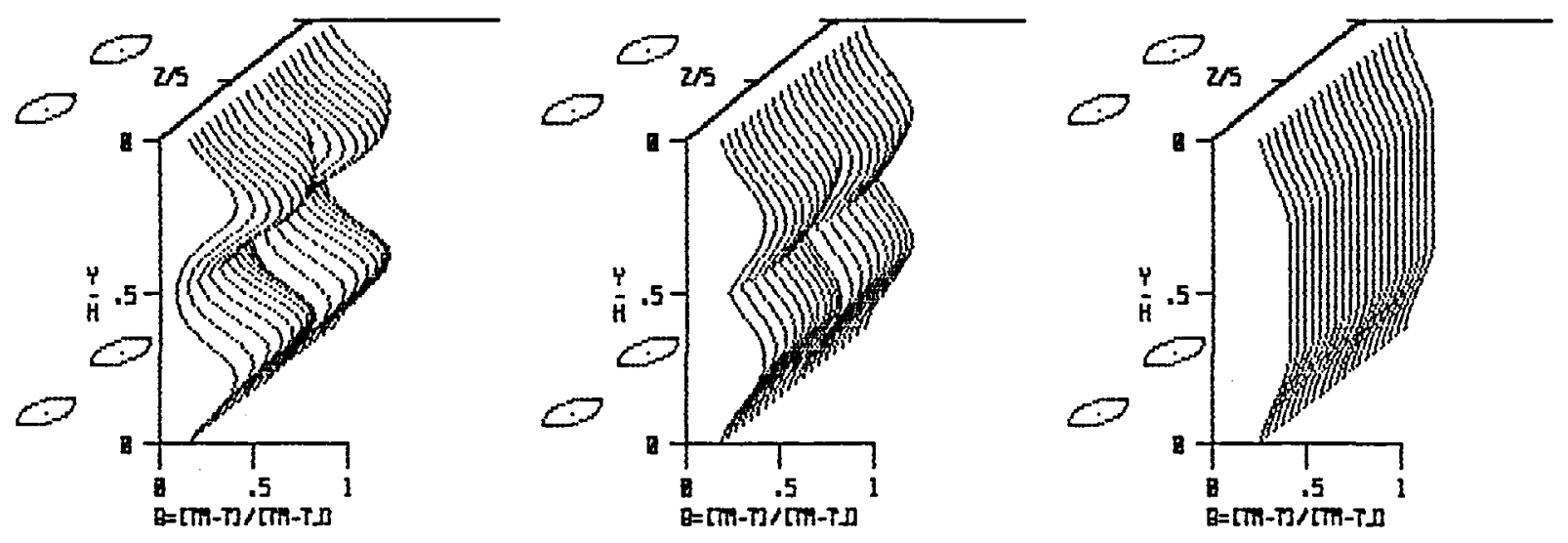

b) $\mathrm{S} / \mathrm{H}_{0}=.25 ; \mathrm{J}=26.4$

Figure 15. Temperature profiles for opposing rows of jets with centerlines in-line $(\mathrm{Ho} / \mathrm{D}=8 ; \mathrm{DR}=2.2 ; \mathrm{Cd}=.64)$. 

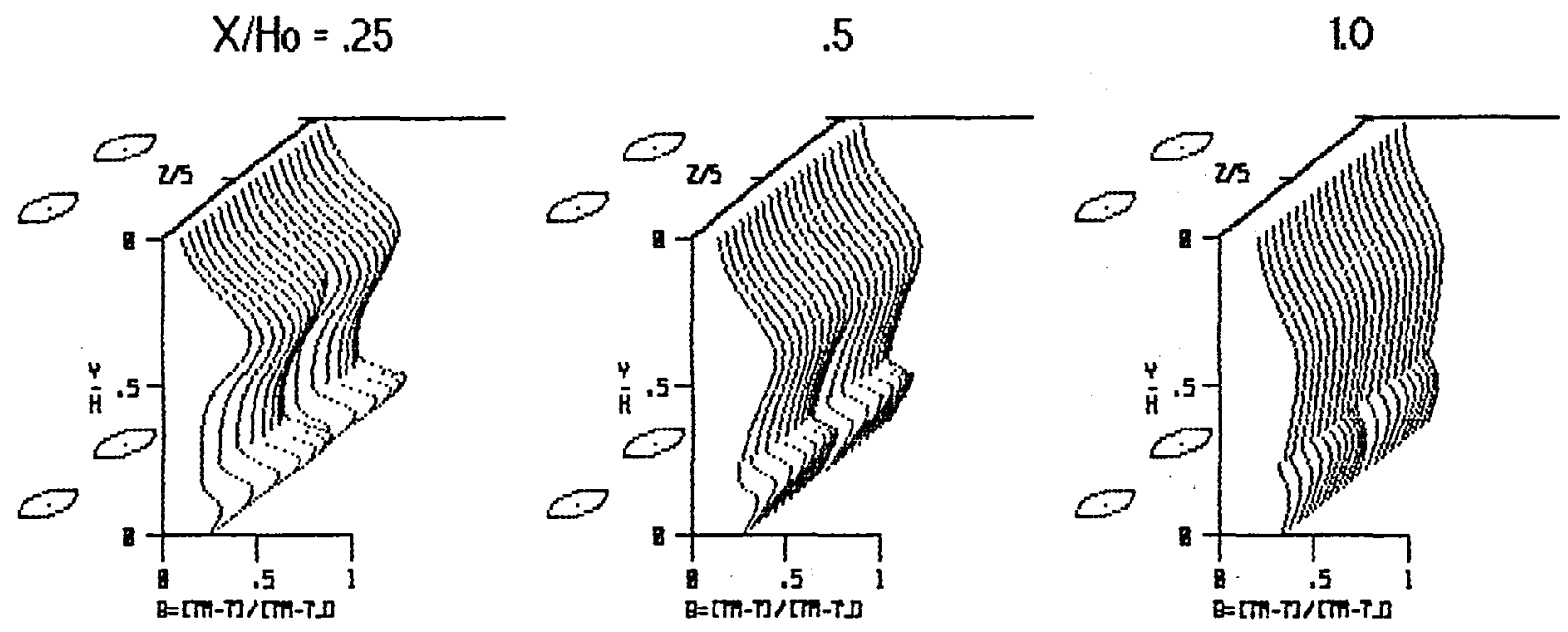

a) $J_{\text {top }}=59.4 ; J_{\text {bottom }}=6.6$
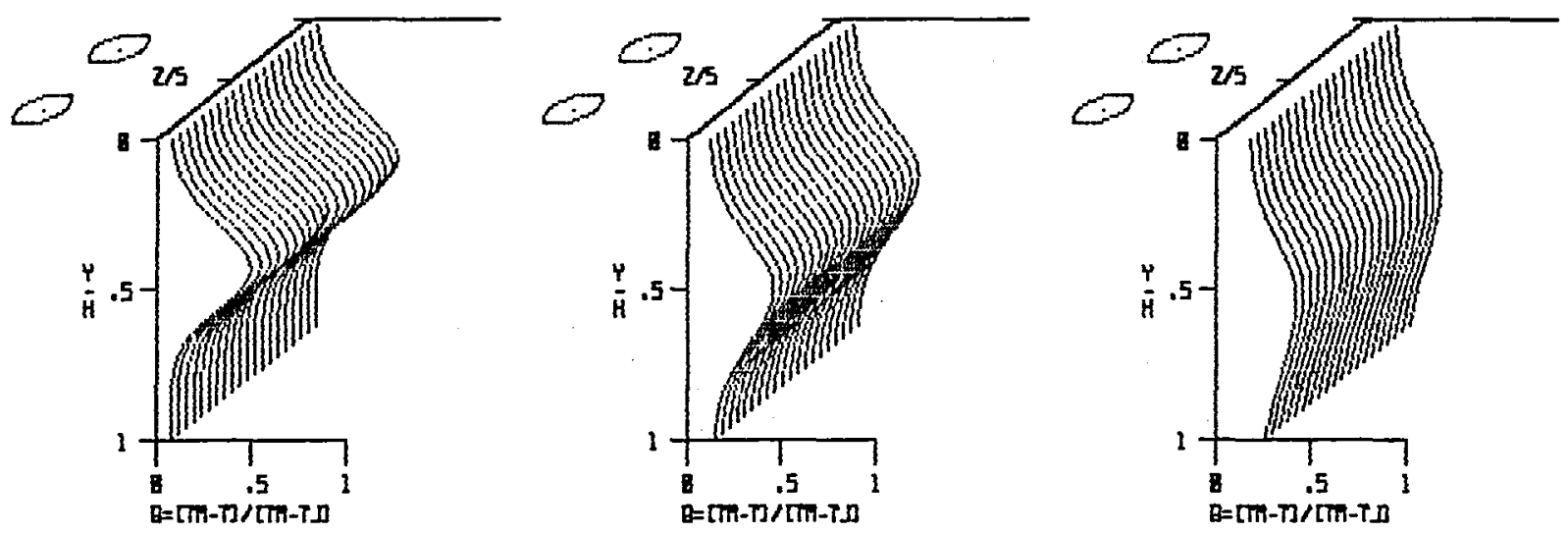

b) $J_{\text {top }}=105.6 ; J_{\text {bottom }}=0$

Figure 16. Temperature profiles for opposing rows of jets with centerlines in-line and unequal momentum flux ratios $(\mathrm{S} / \mathrm{Ho}=.25 ; \mathrm{Ho} / \mathrm{D}=8 ; \mathrm{DR}=2.2 ; \mathrm{Cd}=.64)$. 

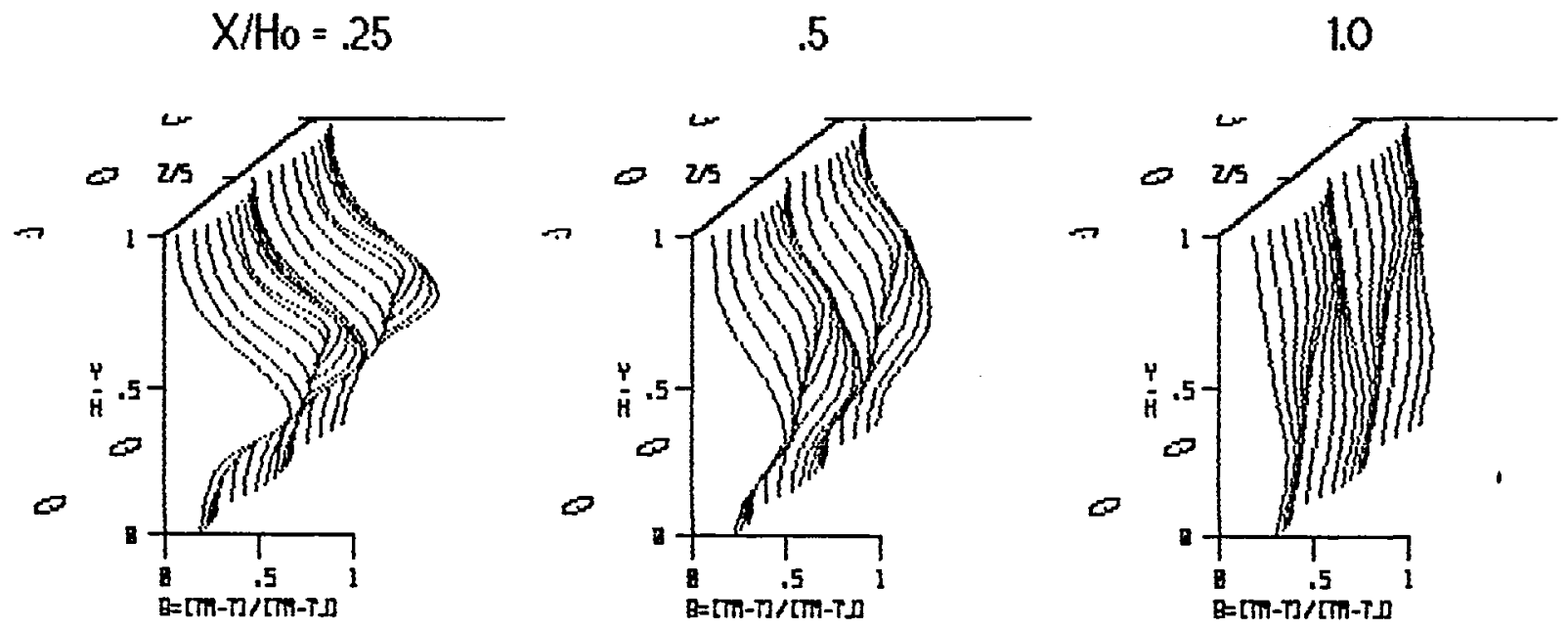

a) $\mathrm{S} / \mathrm{Ho}=1 ; \mathrm{J}=26.4$
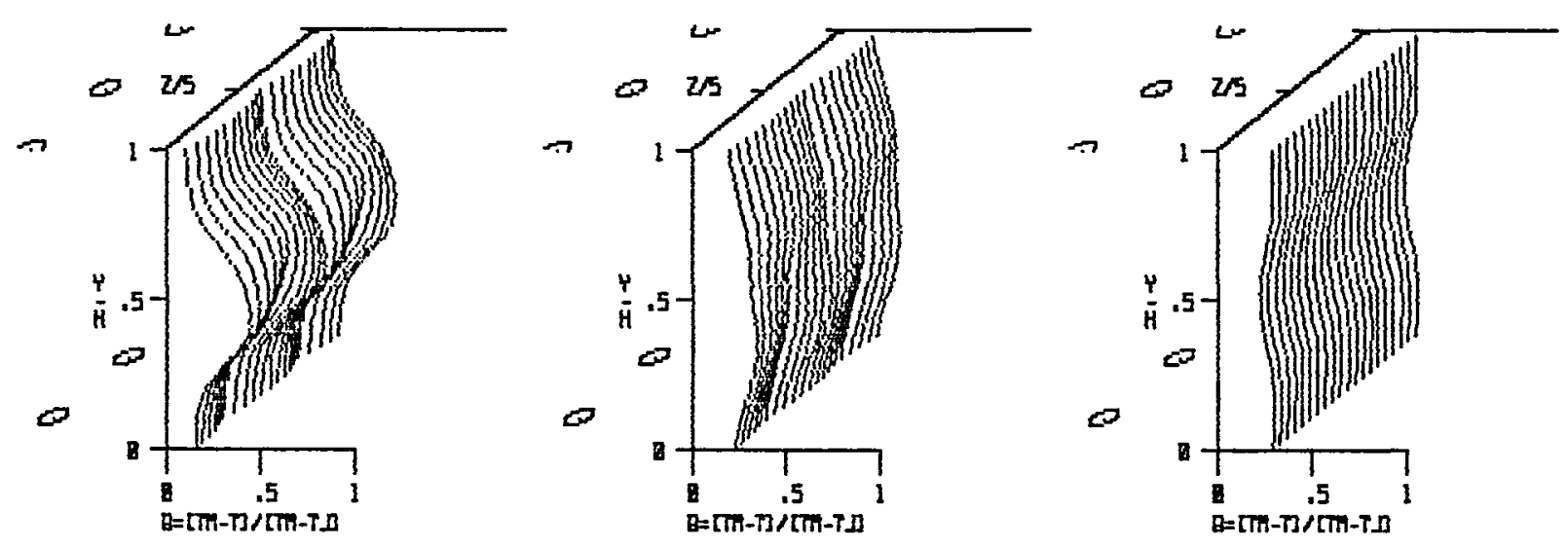

b) $\mathrm{S} / \mathrm{HO}_{0}=.5 ; \mathrm{Ho}_{\mathrm{O}} / \mathrm{D}=8 ; \mathrm{J}=105.6$
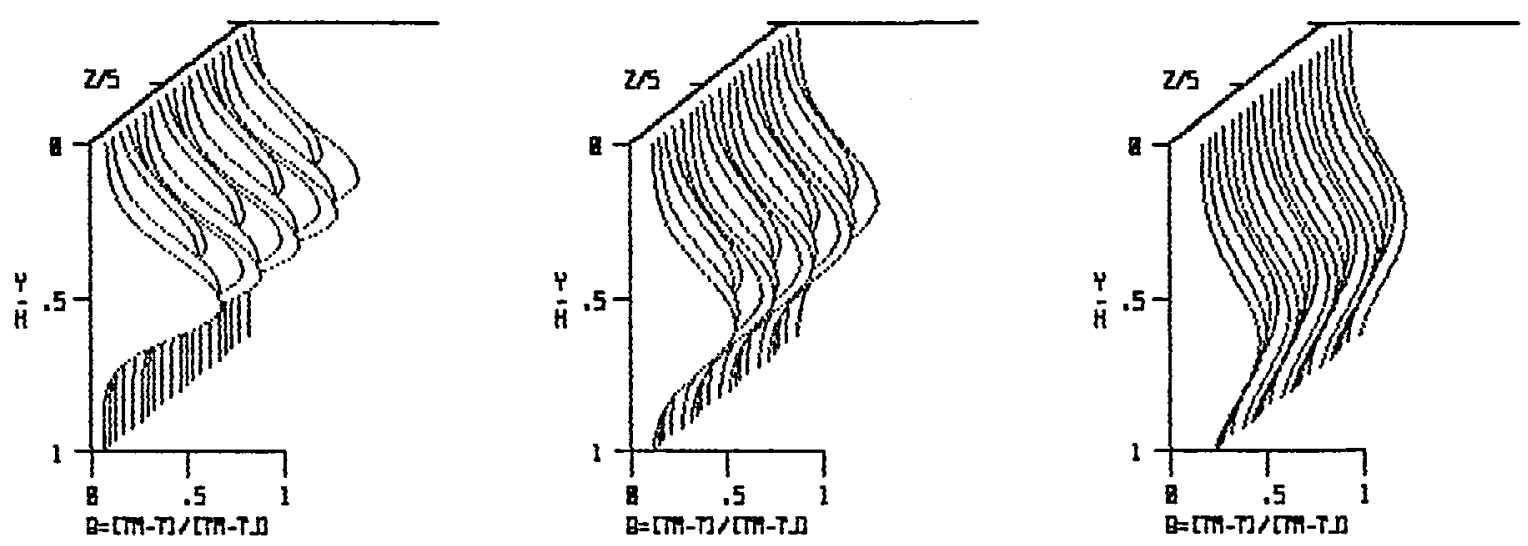

c) single-side; $\mathrm{S} / \mathrm{Ho}_{\mathrm{O}}=.5 ; \mathrm{J}=26.4$

Figure 17. Temperature profiles for opposing rows of jets with centerlines staggered $(\mathrm{DR}=2.2 ; \mathrm{Cd}=.64$ ) 


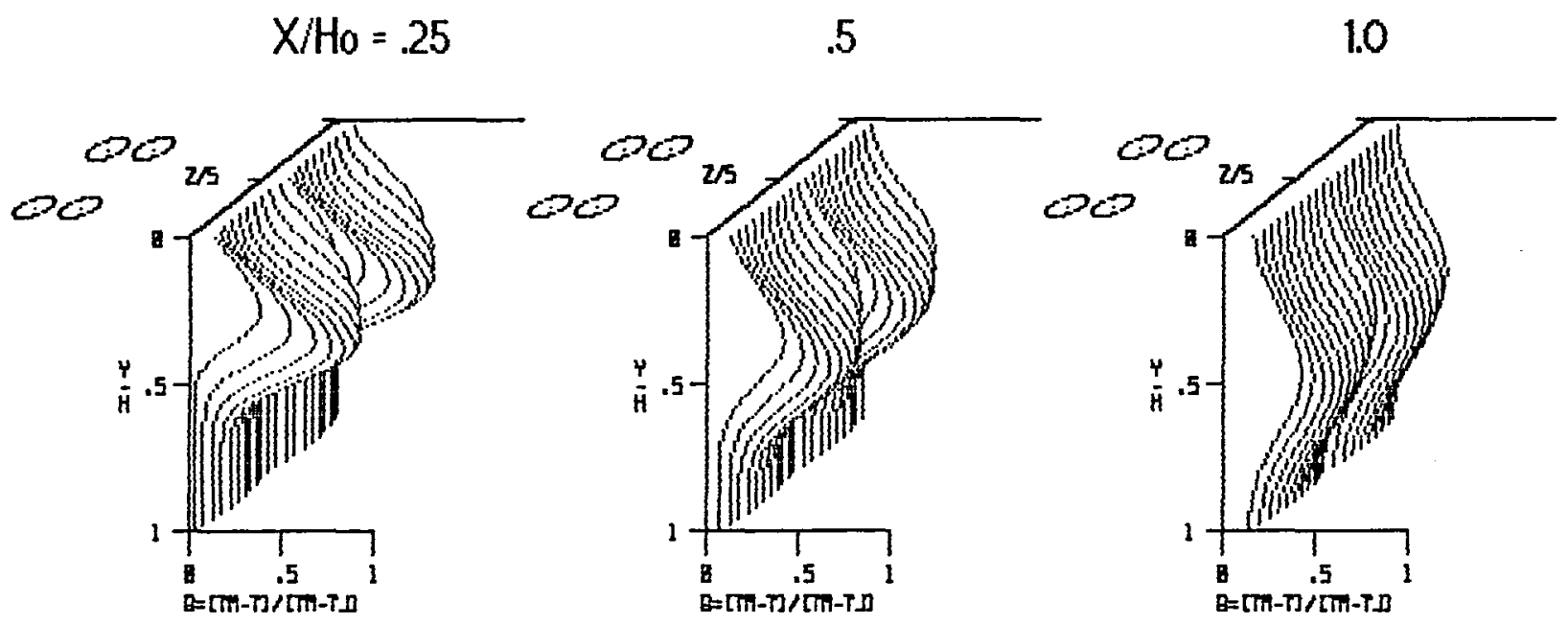

a) $\mathrm{Sx} / \mathrm{H}_{0}=0$

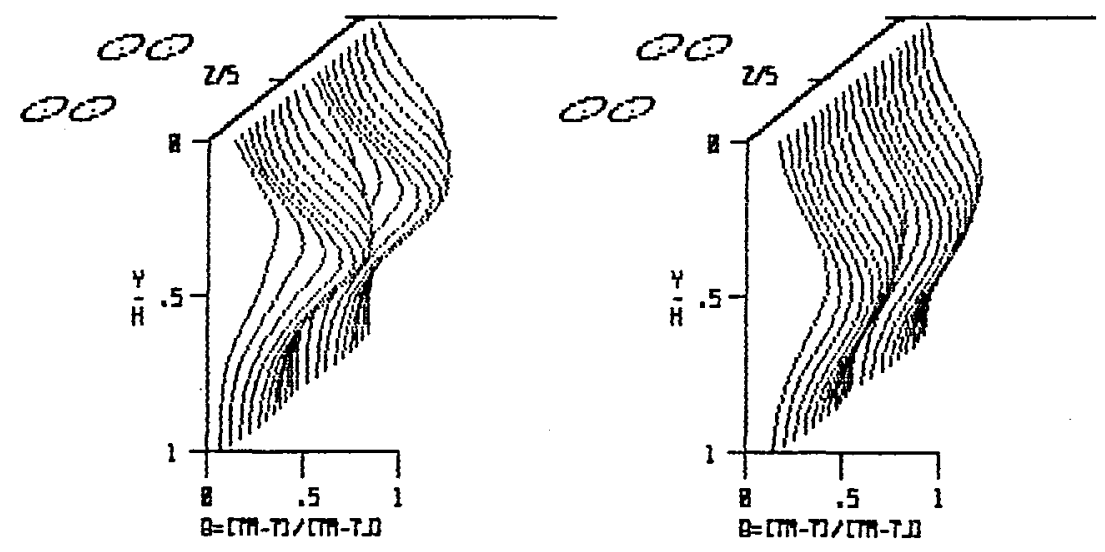

b) $\mathrm{Sx} / \mathrm{H}_{0}=.5$

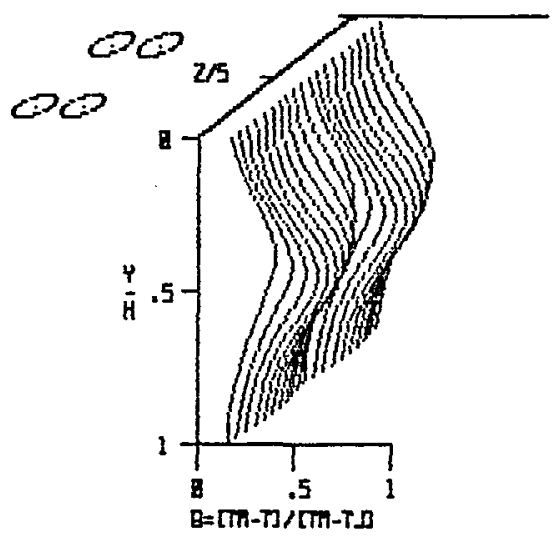

c) $\mathrm{Sx} / \mathrm{H}_{0}=1$

Figure 18. Temperature profiles for double rows of jets with centerlines in-line $\left(\mathrm{S} / \mathrm{Ho}_{\mathrm{O}}=.5 ; \mathrm{Ho} / \mathrm{D}=5.66 ; \mathrm{J}=26.4 ; \mathrm{DR}=2.2 ; \mathrm{Cd}=.64\right.$; downstream distances from midway between rows). 


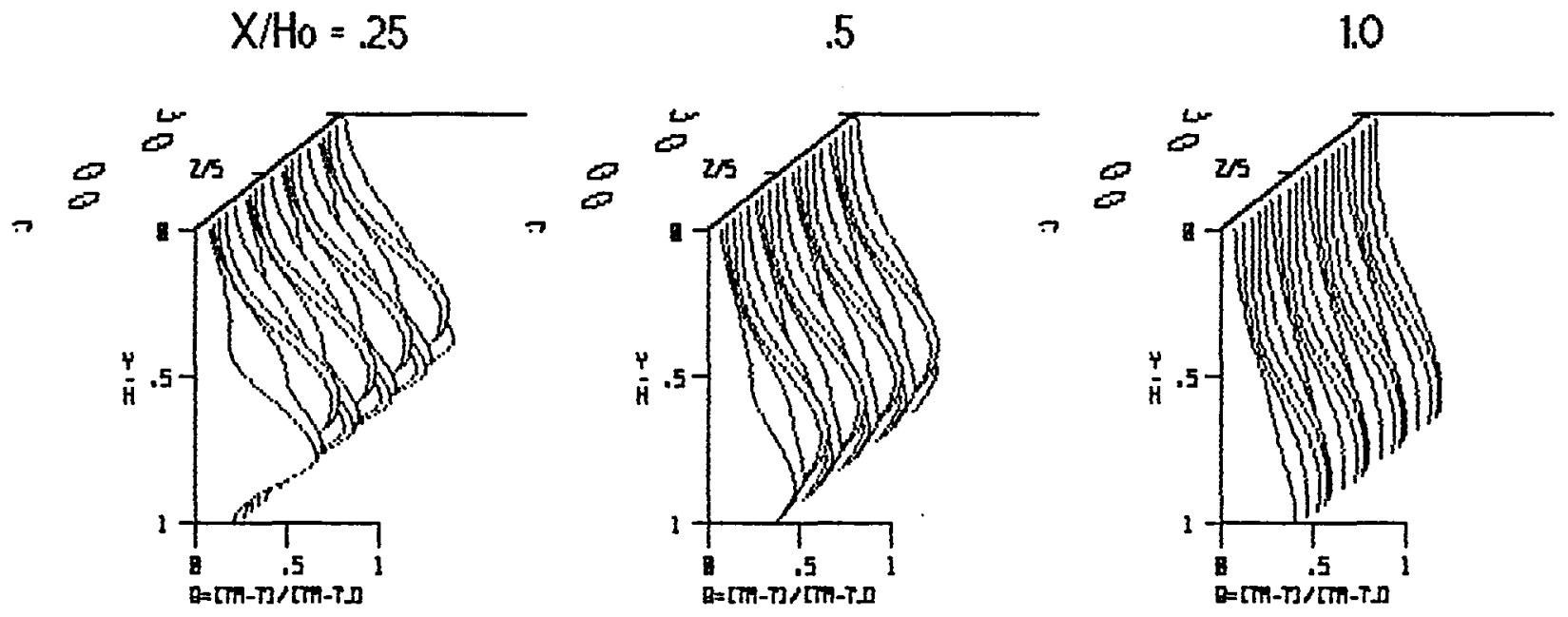

a) $\mathrm{Sx} / \mathrm{H}_{0}=\mathrm{O}$
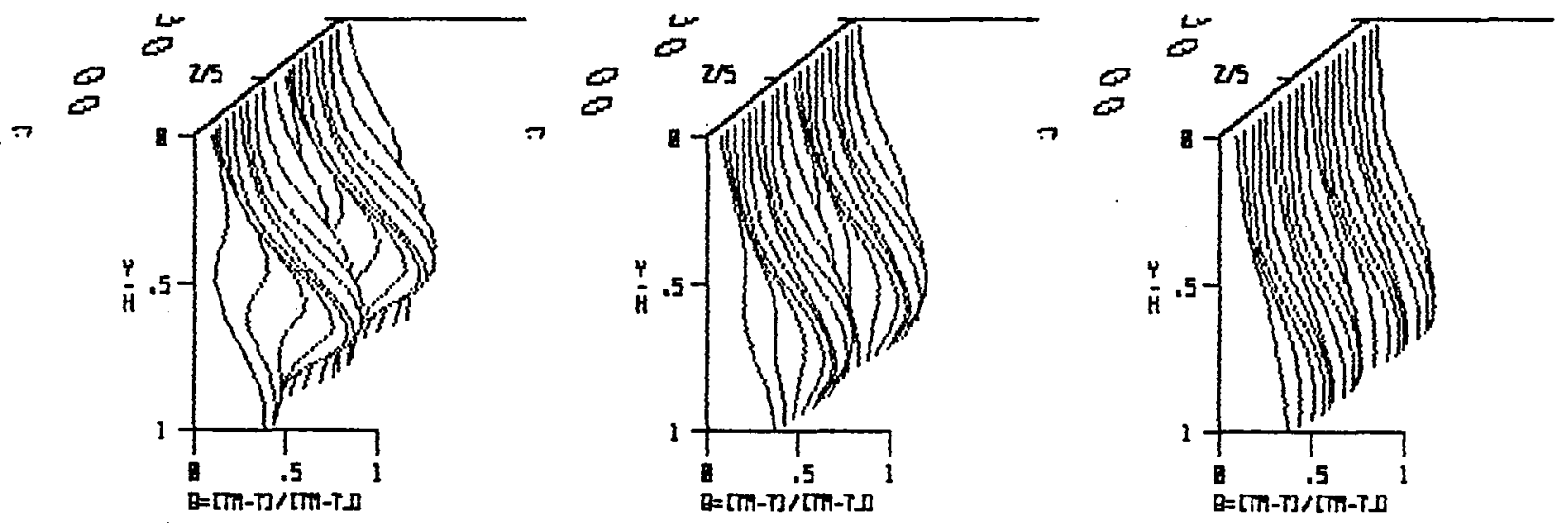

b) $\mathrm{Sx} / \mathrm{H}_{0}=.5$
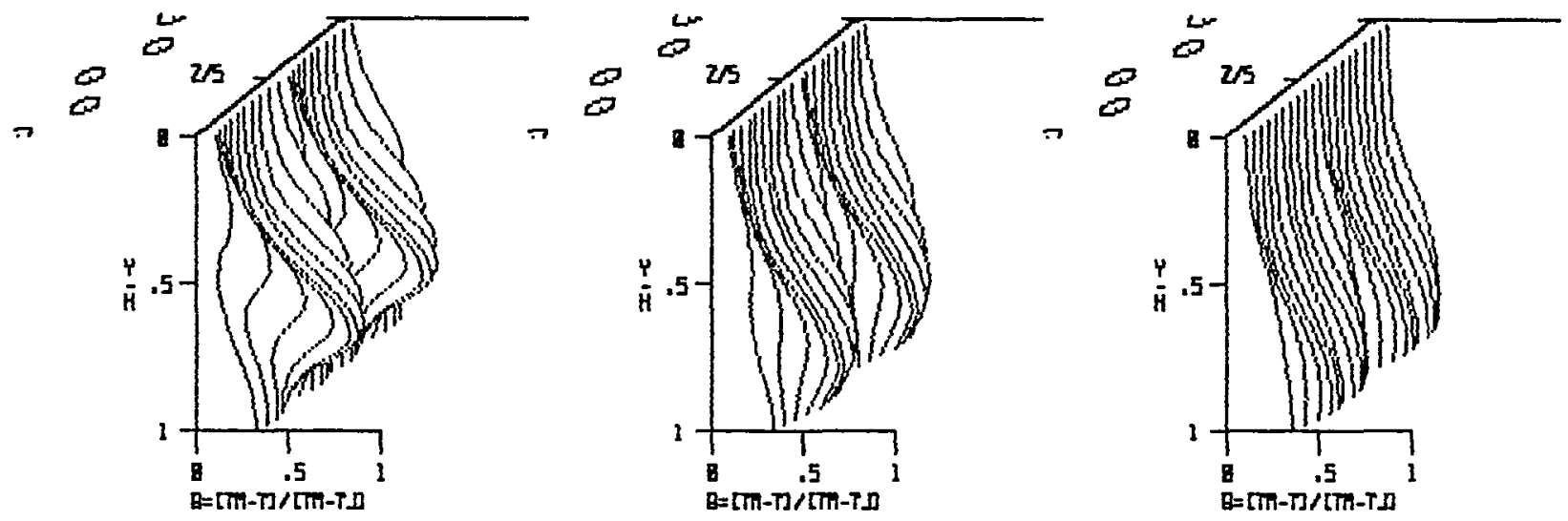

c) $\mathrm{S} x / \mathrm{Ho}_{0}=1$

Figure 19. Temperature profiles for double rows of jets with centerlines staggered $(\mathrm{S} / \mathrm{Ho}=1 ; \mathrm{Ho} / \mathrm{D}=4 ; \mathrm{J}=26.4 ; \mathrm{DR}=2.2 ; \mathrm{Cd}=.64$; downstream distances from trailing row). 
$\mathrm{X} / \mathrm{H}_{0}=.25$

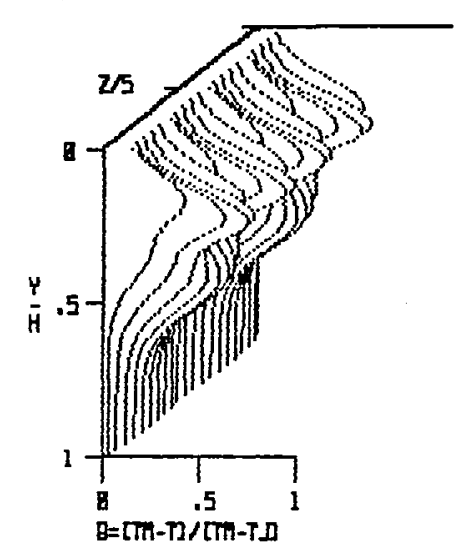

a) $J_{\text {front }}=J_{\text {rear }}=26.4$

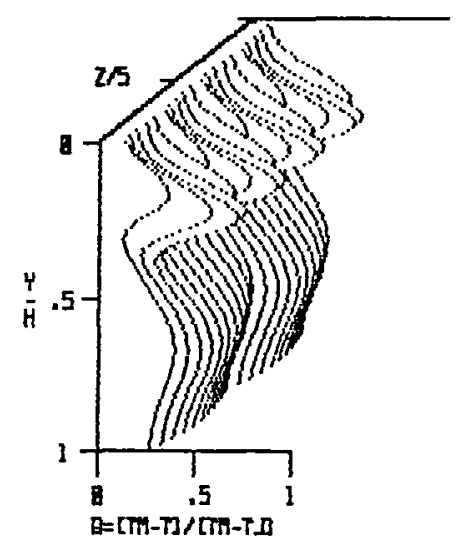

b) $J_{\text {front }}=105.6 ; J_{\text {rear }}=26.4$

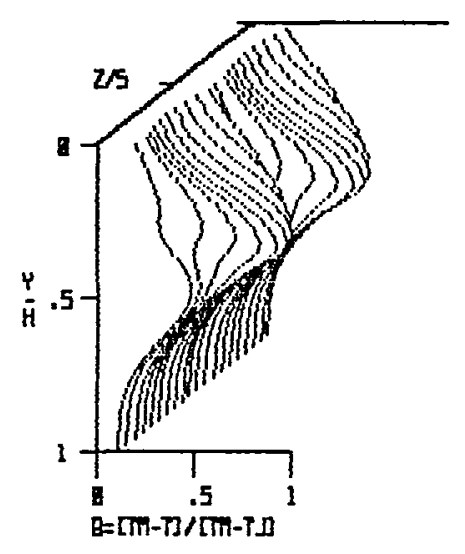

.5
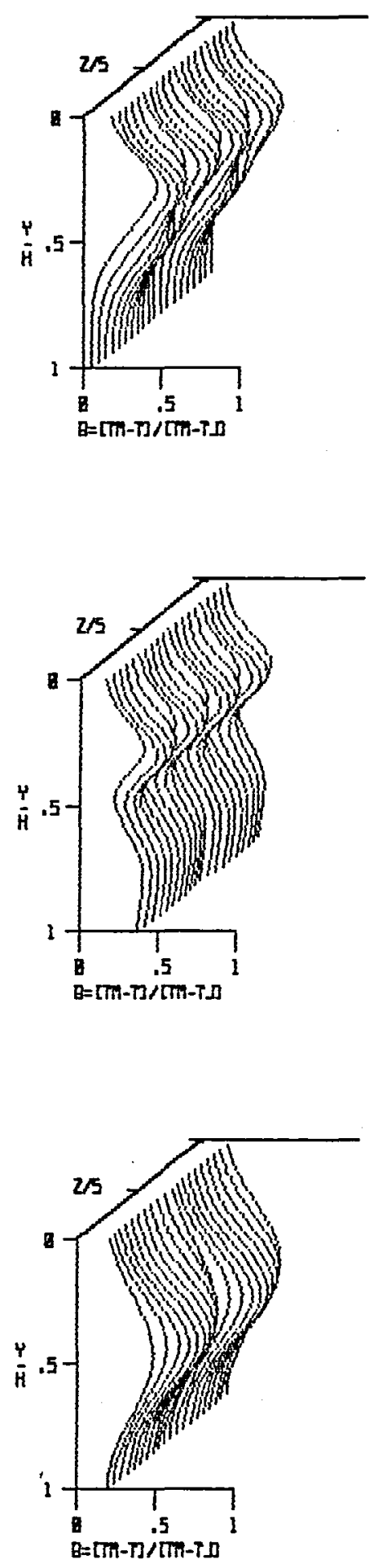

1.0

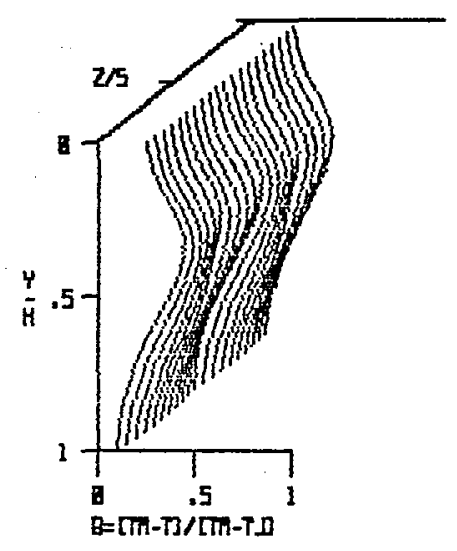

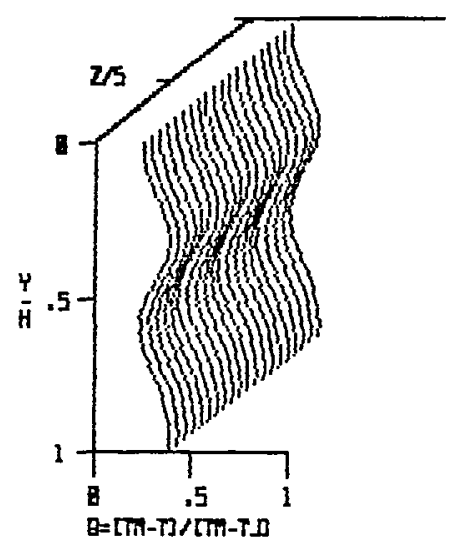

c) Jfront $=105.6 ; J_{\text {rear }}=26.4$

Figure 20. Temperature profiles for double rows of jets with different orifice size and spacing in each row; $\mathrm{Sx} / \mathrm{Ho}=.25$ (Row $1: \mathrm{S} / \mathrm{Ho}=.5 ; \mathrm{Ho} / \mathrm{D}=5.66$; Row $2: \mathrm{S} / \mathrm{Ho}=.25 ; \mathrm{Ho} / \mathrm{D}=8$; Both: $\mathrm{DR}=2.2 ; \mathrm{Cd}=.64)$. 


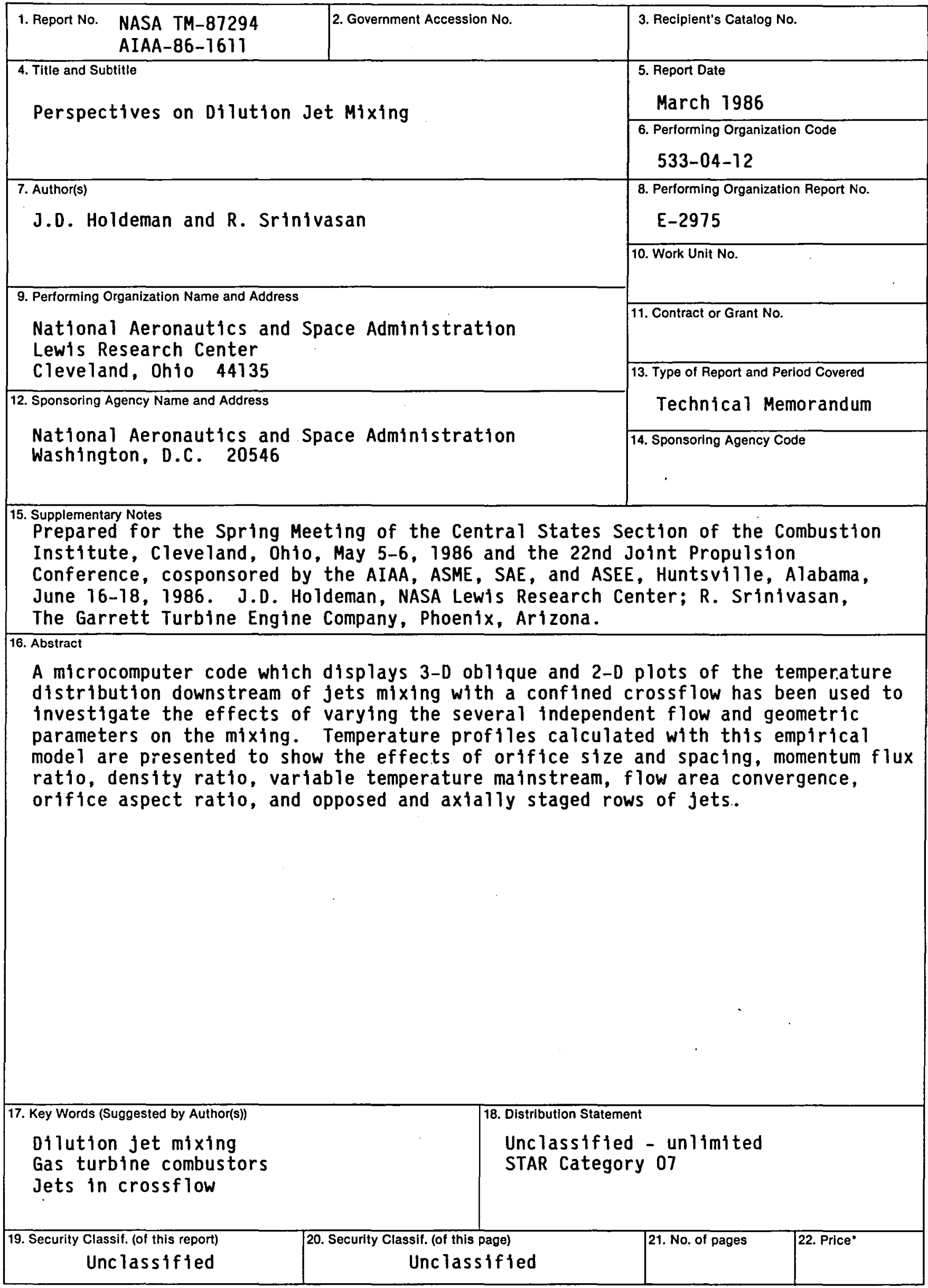

*For sale by the National Technical Information Service, Springfield, Virginia 22161 
End of Document 